\title{
Optimal thermal and thermodynamic performance of a solar parabolic trough receiver with different nanofluids and at different concentration ratios
}

\author{
Aggrey Mwesigye $^{1 \dagger}$, Josua P. Meyer ${ }^{2}$ \\ ${ }^{1}$ School of Mechanical, Industrial and Aeronautical Engineering, University of the \\ Witwatersrand, Johannesburg, Private Bag 3, Wits 2050, Johannesburg, South Africa \\ ${ }^{2}$ Department of Mechanical and Aeronautical Engineering, University of Pretoria \\ Private Bag X20, Hatfield 0028, South Africa
}

\section{Highlights}

- Optimal thermal and thermodynamic analysis of a parabolic trough receiver with different nanofluids.

- Performance at different concentration ratios with nanofluids is investigated.

- Presence of an optimal thermal efficiency value at each volume fraction is shown.

- Improvement in thermal performance was greater at higher concentration ratios than lower ones.

- Correlation for the Reynolds number that gives improved thermodynamic performance is presented.

\begin{abstract}
In this paper, the optimum thermal and thermodynamic operating conditions of a parabolic trough solar energy system working with copper-Therminol ${ }^{\circledR} \mathrm{VP}-1$, silver-Therminol ${ }^{\circledR} \mathrm{VP}-1$ and $\mathrm{Al}_{2} \mathrm{O}_{3}$-Therminol ${ }^{\circledR} \mathrm{VP}-1$ nanofluids as heat transfer fluids were investigated. Moreover, the influence of increasing concentration ratios on the thermal and thermodynamic optimum conditions was considered for concentration ratios between 88 and 113 . To obtain the system's precise thermal and thermodynamic performance, a well-validated numerical model, with a typical heat flux profile on the outer wall of the receiver's absorber tube, was developed using a finite volume based computational fluid dynamics tool together with Monte Carlo ray tracing. Results show that silver-Therminol ${ }^{\circledR} \mathrm{VP}-1$ nanofluid gives the highest thermal performance
\end{abstract}

\footnotetext{
${ }^{\dagger}$ Corresponding author: Tel: +27 11717 7378, Fax: +27 117177049

Email address: Aggrey.Mwesigye@wits.ac.za
} 
owing to its comparatively better thermal transport properties, whereas $\mathrm{Al}_{2} \mathrm{O}_{3}$-Therminol ${ }^{\circledR} \mathrm{VP}-1$ showed the lowest thermal performance. Given the increase in the useful energy gain from the collector with heat transfer enhancement, the thermal efficiency was shown to increase by $13.9 \%, 12.5 \%$ and $7.2 \%$ for silver-Therminol ${ }^{\circledR} \mathrm{VP}-1$, copper-Therminol ${ }^{\circledR} \mathrm{VP}-1$ and $\mathrm{Al}_{2} \mathrm{O}_{3}{ }^{-}$ Therminol ${ }^{\circledR} \mathrm{VP}-1$, respectively when the concentration ratio is 113 . With increasing concentration ratios, the increase in thermal efficiency at a concentration ratio of 113 was shown to be about $5 \%$ higher than the increase at a concentration ratio of 88 . The optimal thermal performance was nearly at the same flow rate of about $22.5 \mathrm{~m}^{3} \mathrm{~h}^{-1}$ for all the nanofluids and concentration ratios. The optimal thermodynamic performance for low exergy destruction was mainly dependent on the inlet temperature used. Correlations for the Reynolds numbers that give improved thermodynamic performance were derived and presented.

Keywords: Computational fluid dynamics, concentration ratio, nanofluid, optimum thermodynamic performance, parabolic trough receiver

\section{Nomenclature}

$\begin{array}{ll}A_{a} & \text { Collector's projected aperture area, } \mathrm{m}^{2} \\ A_{r o} & \text { Absorber tube outer wall surface area, } \mathrm{m}^{2} \\ A_{g} & \text { Silver } \\ B e & \text { Bejan number defined as } B e=\left(S_{g e n}\right)_{H} S_{g e n} \\ C_{l}, C_{2}, C_{\mu} & \text { Constants for the realisable } k-\varepsilon \text { turbulence model } \\ c_{f} & \text { Coefficient of friction } \\ C_{R} & \text { Geometric concentration ratio } \\ c_{p} & \text { Specific heat capacity, } \mathrm{J} \mathrm{kg}^{-1} \mathrm{~K}^{-1} \\ C u & \text { Copper } \\ D & \text { Tube diameter, } \mathrm{m} \\ I_{b} & \text { Direct normal irradiance, } \mathrm{W} \mathrm{m}^{-2} \\ d_{g i} & \text { Inner diameter of the receiver's glass cover, } \mathrm{m}\end{array}$




\begin{tabular}{|c|c|}
\hline$d_{g o}$ & Outer diameter of the receiver's glass cover, $\mathrm{m}$ \\
\hline$d_{r i}$ & Inner diameter of the absorber tube, $\mathrm{m}$ \\
\hline$d_{r o}$ & Outer diameter of the absorber tube, $\mathrm{m}$ \\
\hline$F$ & Collector focal length, $\mathrm{m}$ \\
\hline$G$ & Mass flux, $\mathrm{kg} \mathrm{s}^{-1} \mathrm{~m}^{-2}$ \\
\hline$G_{k}$ & Generation of turbulent kinetic energy due to mean velocity gradients, $\mathrm{kg} \mathrm{m}^{-1} \mathrm{~s}^{-3}$ \\
\hline$h$ & Heat transfer coefficient, $\mathrm{W} \mathrm{m}{ }^{-2} \mathrm{~K}^{-1}$ \\
\hline$h_{w}$ & Outer glass cover wall heat transfer coefficient, $\mathrm{W} \mathrm{m}^{-2} \mathrm{~K}^{-1}$ \\
\hline$k$ & Turbulent kinetic energy, $\mathrm{m}^{2} \mathrm{~s}^{-2}$ \\
\hline$L$ & Length, $\mathrm{m}$ \\
\hline$L C R$ & Local concentration ratio \\
\hline $\mathrm{Nu}$ & Nusselt number \\
\hline$R e$ & Reynolds number \\
\hline$\dot{m}$ & Mass flow rate, $\mathrm{kg} \mathrm{s}^{-1}$ \\
\hline$P$ & Pressure, $\mathrm{Pa}$ \\
\hline$q^{\prime}$ & Heat transfer rate per unit length, $\mathrm{W} \mathrm{m}^{-1}$ \\
\hline$q^{\prime \prime}$ & Heat flux, $\mathrm{W} \mathrm{m}^{-2}$ \\
\hline$\dot{Q}_{u}$ & Useful energy delivered, $\mathrm{W}$ \\
\hline$\dot{Q}_{\text {loss }}$ & Receiver thermal loss, $\mathrm{W}$ \\
\hline$S$ & Modulus of the mean rate-of-strain tensor, $\mathrm{s}^{-1}$ \\
\hline$S_{i j}$ & Rate of linear deformation tensor, $\mathrm{s}^{-1}$ \\
\hline$S_{\text {gen }}$ & Total entropy generation rate, $\mathrm{W} \mathrm{K}^{-1}$ \\
\hline$S_{g e n}^{\prime}$ & Entropy generation per unit length, $\mathrm{W} \mathrm{m}{ }^{-1} \mathrm{~K}^{-1}$ \\
\hline$S^{\prime \prime \prime}{ }_{g e n}$ & Entropy generation rate per unit volume, $\mathrm{W} \mathrm{m}^{-3} \mathrm{~K}^{-1}$ \\
\hline$\left(S^{\prime \prime \prime}{ }_{g e n}\right)_{F}$ & Entropy generation rate per unit volume due to fluid friction, $\mathrm{W} \mathrm{m}^{-3} \mathrm{~K}^{-1}$ \\
\hline$\left(S^{\prime \prime \prime}{ }_{g e n}\right)_{H}$ & Entropy generation rate per unit volume due to heat transfer, $\mathrm{W} \mathrm{m}^{-3} \mathrm{~K}^{-1}$ \\
\hline
\end{tabular}




$\begin{array}{ll}T & \text { Temperature, } \mathrm{K} \\ U_{L} & \text { Overall heat transfer coefficient, } \mathrm{W} \mathrm{m}^{-2} \mathrm{~K}^{-1} \\ u & \text { Average flow velocity, } \mathrm{m} \mathrm{s}^{-1} \\ u_{i}, u_{j} & \text { Velocity components, } \mathrm{m} \mathrm{s}^{-1} \\ u^{\prime}, v^{\prime}, w^{\prime} & \text { Velocity fluctuations, } \mathrm{m} \mathrm{s}^{-1} \\ u_{\tau} & \text { Friction velocity }\left(\mu_{\tau}=\sqrt{\tau_{w} / \rho}\right), \mathrm{m} \mathrm{s}^{-1} \\ V & \text { Volume, } \mathrm{m}^{3} \\ V_{w} & \text { Wind velocity, } \mathrm{m} \mathrm{s}^{-1} \\ \dot{V} & \text { Flow rate, } \mathrm{m}^{3} \mathrm{~s}^{-1} \\ W & \text { Collector aperture width, } \mathrm{m} \\ \dot{W}_{p} & \text { Pumping power, } \mathrm{W} \\ x, y, z & \text { Cartesian coordinates } \\ y^{+} & \text {Dimensionless wall coordinate } \\ -\rho \overline{u_{i}^{\prime} u_{j}^{\prime}} & \text { Reynolds stresses, } \mathrm{N} \mathrm{m} \mathrm{m}^{-2} \\ \Delta P & \text { Pressure drop, Pa }\end{array}$

\section{Greek letters}

$\alpha$

$\alpha_{t}$

$\alpha_{a b s}$

$\sigma$

$\sigma_{h . t}$

$\sigma_{\varepsilon}$

$\sigma_{k}$

$\sigma_{\text {slope }}$

$\sigma_{\text {spec }}$

$\delta_{i j}$
Thermal diffusivity, $\mathrm{m}^{2} \mathrm{~s}^{-1}$

Turbulent thermal diffusivity, $\mathrm{m}^{2} \mathrm{~s}^{-1}$

Absorptivity of the absorber tube's selective coating

Stefan Boltzmann constant, $\mathrm{W} \mathrm{m}^{-2} \mathrm{~K}^{-4}$

Prandtl number for energy

Prandtl number for the transport of the turbulent dissipation rate, $\varepsilon$

Prandtl number for the transport of turbulent kinetic energy, $k$

Mirror slope error, mrad

Mirror specularity error, mrad

Kronecker delta 


\begin{tabular}{|c|c|}
\hline$\varepsilon$ & Turbulent dissipation rate, $\mathrm{m}^{2} \mathrm{~s}^{-3}$ \\
\hline$\varepsilon_{g}$ & Emissivity of the glass cover \\
\hline$\varepsilon_{r o}$ & Emissivity of the absorber tube's outer wall \\
\hline$\eta$ & Turbulence model parameter $=S k / \varepsilon$ \\
\hline$\eta_{o}$ & Optical efficiency, \% \\
\hline$\eta_{t h}$ & Receiver thermal efficiency, \% \\
\hline$\eta_{e}$ & Electrical efficiency of the power block, $\%$ \\
\hline$\varphi_{r}$ & Collector rim angle, degrees \\
\hline$\phi$ & Volume fraction \\
\hline$\theta$ & Receiver circumferential angle, degrees \\
\hline$\rho$ & Density, $\mathrm{kg} \mathrm{m}^{-3}$ \\
\hline$\rho$ & Reflectivity of the collector mirror \\
\hline$\tau_{g}$ & Transmissivity of the glass cover \\
\hline$\tau_{w}$ & Wall shear stress, $\mathrm{N} \mathrm{m}^{-2}$ \\
\hline$\lambda$ & Fluid thermal conductivity, $\mathrm{W} \mathrm{m} \mathrm{m}^{-1} \mathrm{~K}^{-1}$ \\
\hline$\mu$ & Viscosity, Pa s \\
\hline$\mu_{t}$ & Eddy viscosity, Pa s \\
\hline$v$ & Kinematic viscosity of the heat transfer fluid, $\mathrm{m}^{2} \mathrm{~s}^{-1}$ \\
\hline
\end{tabular}

\section{Subscripts}

$\begin{array}{ll}a & \text { Ambient conditions } \\ b & \text { Base fluid } \\ b u l k & \text { Bulk flow conditions } \\ F & \text { Fluid flow irreversibility } \\ g i & \text { Inner side of the receiver glass cover } \\ g o & \text { Outer side of the receiver glass cover } \\ H & \text { Irreversibility due to heat transfer } \\ i, j, k & \text { General spatial indices }\end{array}$




$\begin{array}{ll}\text { in } & \text { Inlet conditions } \\ n f & \text { nanofluid } \\ \text { out } & \text { Outlet conditions } \\ p & \text { nanoparticle } \\ r i & \text { Inner side of the absorber tube } \\ r o & \text { Outer side of the absorber tube } \\ s k y & \text { Sky conditions } \\ t & \text { Turbulent }\end{array}$

\section{Superscripts}

$\begin{array}{ll}- & \text { Time-averaged value } \\ \sim & \text { Fluctuation from mean value } \\ & \text { Dimensionless parameter }\end{array}$

\section{Introduction}

It is widely acknowledged that the continued utilisation of fossil fuels is not sustainable owing to the harm these fuels cause to the environment. Fossil fuels are non-renewable and the $\mathrm{CO}_{2}$ emitted from power plants and energy systems using fossil fuels has exacerbated global warming and climate change. Moreover, there are increasing concerns related to security of energy supply as well as the need to meet the ever increasing demand for energy. The increasing demand for energy is mainly due to the high industrialisation, population growth and urbanisation rates experienced in most countries [1]. To meet this increasing demand for energy with little or no harm to the environment while ensuring security of energy supply, alternative, widely available, clean and renewable energy sources have to be sought and developed.

A number of renewable energy resources exist to provide the needed shift from conventional fossil-based resources. These resources include geothermal, wind energy, bioenergy and solar energy. Solar energy is among the most widely available resources with significant potential to provide the much-needed energy. Solar thermal energy technologies are receiving increasing 
attention, given that it is easier to store thermal energy and dispatch it when the sun is not shining [1]. Solar thermal energy technologies that are at the commercial or nearly at the commercial stage include the solar tower, parabolic dish, parabolic trough and linear Fresnel systems. These concentrating systems give higher heat transfer fluid temperatures, which result in increased thermal efficiencies of the power block.

The parabolic trough solar energy systems contribute almost $90 \%$ of all the energy available from concentrated solar power systems [2]. Therefore, these systems are the most technically and commercially developed solar thermal systems available today. Despite this, the energy from these systems is still considerably expensive than that from fossil-fuelled power plants. Without government incentives and subsidies, the cost of energy from these systems is twice that from fossil-fuelled power plants [3]. To make energy from these systems cost competitive, a number of research initiatives are underway. These initiatives include the development of durable absorber tube coatings, low-cost and high-performance reflectors, high-temperature heat transfer fluids, high-concentration ratio systems, reliable receiver tubes, improved thermal storage solutions and many more [3-5].

Large aperture or high-concentration ratio systems have several advantages, such as shorter solar collector assemblies, which lead to less drives and controls. Moreover, with high concentration ratios, the useful energy gain from the collector will increase. There is therefore potential for increased energy output and cost reductions with high concentration ratio parabolic trough systems. This will likely make these systems cost competitive with conventional energy systems, leading to increased adoption of the technology and assisting in meeting the increasing energy demand as well as in mitigating climate change through reduced emission of greenhouse gases. Recently, large aperture width systems have been developed owing to the advances in lightweight materials and advanced manufacturing technologies [6,7]. Since the construction of the first solar electric generating systems (SEGS) in the 1980s, which have been in operation ever since, the concentration ratios of these systems have continued to increase. The concentration ratios have increased from 61 (2.55 m collector aperture width and $40 \mathrm{~mm}$ receiver diameter) [8] to current systems under development with concentration ratios up to 114 (8 $\mathrm{m}$ collector aperture and $70 \mathrm{~mm}$ receiver absorber tube diameter) $[9,10]$. 
With increasing concentration ratios, efficient heat transfer performance will be essential not only to improve the performance of these systems, but also to mitigate some of the challenges that affected the parabolic trough solar energy systems during their earlier development stages. These challenges included excessive receiver failures owing to the receiver temperature gradients resulting from the non-uniform nature of the heat flux distribution on the absorber tube[4], loss of receiver vacuum due to permeation of hydrogen as the heat transfer fluid degrades at temperatures above $400{ }^{\circ} \mathrm{C}$. Moreover, with high concentration ratios and the resulting high absorber tube temperatures, heat transfer irreversibilities increase significantly. As such, convective heat transfer enhancement in the absorber tube of the receiver will play a noteworthy role in reducing the tube's temperature gradients, and improve the overall system performance, as well as improve the reliability of these systems as concentration ratios increase.

There has recently been significant interest in the enhancement of convective heat transfer performance of receivers for parabolic trough solar energy systems. A number of studies have shown that convective heat transfer enhancement in the receiver's absorber tube improves the performance of these systems. Ravi Kumar and Reddy [11] performed a thermal analysis on a parabolic trough receiver with a porous disc oriented at different angles. Heat transfer was enhanced by about $64.3 \%$. In a study on the use of centrally placed perforated plate inserts in the receiver's absorber tube by Mwesigye et al. [12], the temperature gradients were shown to reduce by about $33 \%$ and the thermal efficiency was shown to improve by up to $8 \%$. Muñoz and Abánades [13] investigated the use of internal helical fins to improve receiver performance. The receiver's thermal losses reduced by up to $18 \%$ and the temperature difference between the internal and external tube reduced by $40 \%$. The thermal efficiency of the system increased by about 3\%. Fuqiang et al. [14] considered the use of a corrugated absorber tube to improve the receiver heat transfer and thermal deformation characteristics. The effective heat transfer coefficient was shown to increase by $8.4 \%$, while the maximum thermal strain could be reduced by $13.1 \%$. In their recent study, Fuqiang et al. [15] used an asymmetric outward convex corrugated tube to improve the receiver performance and restrain the thermal strain in a parabolic trough receiver. The von-Mises strain was reduced by $26.8 \%$ and a thermal enhancement performance factor of about $148 \%$ was achieved. Wang et al. [16] considered the use of metal foams in a direct steam generation parabolic trough receiver. At optimum performance, a 
maximum reduction in the circumferential temperature difference of about $45 \%$ was achieved with performance evaluation criteria values ranging from 1.4 to 3.2. Cheng et al. [17] performed a numerical analysis on the use of unilateral vortex generators in the receiver's absorber tube. The receiver thermal loss was shown to reduce by between 2.23 and $13.62 \%$.

Thus far, the studies reviewed considered the use of passive heat transfer enhancement techniques to improve the thermal performance of the receiver tube of a parabolic trough solar energy system. These heat transfer enhancement techniques include modification of the absorber tube's wall to increase the heat transfer area and the use of inserts to facilitate the mixing of the heat transfer fluid. Improving the thermal properties of the heat transfer fluid is another way of improving the performance of the receiver without modifying its geometry. The dispersion of high thermal conductivity nano-sized particles in a base fluid to form a nanofluid is one way of improving the thermal transport properties of the commonly used heat transfer fluids. Suspension of nano-sized particles, usually with diameters between 1-100 $\mathrm{nm}$ in a base fluid is what is refereed to as a nanofluid [18].

From available literature, there is consensus that the improvement in the thermal conductivity of the base fluid with the use of nanofluids is the most important factor that influences thermal performance of solar energy systems [19]. As such, several studies on the determination of thermal conductivity enhancements and other important properties of nanofluids have been undertaken by a number of researchers. For example, Li et al. [20] showed that the thermal conductivity of diathermic oil for high temperature applications could be enhanced by up to $7.36 \%$ by suspending $\mathrm{SiC}$ nanoparticles with a volume fraction of $0.8 \%$. In a study by Lee et al. [21], thermal conductivity enhancements of up to $15 \%$ were obtained using $\mathrm{Al}_{2} \mathrm{O}_{3}$ with a volume fraction of $4.3 \%$ in water or ethylene glycol. In the measurement of thermal conductivity, viscosity and stability of $\mathrm{Al}_{2} \mathrm{O}_{3}$ - diathermic oil nanofluids for solar energy systems, Colangelo et al. [22] obtained thermal conductivity enhancements of $3 \%$ and $4 \%$ at volume fraction of $0.7 \%$ and $1 \%$, respectively. The authors further show that the use of surfactants greatly improves the stability of the nanofluids. In another related study, Colangelo et al. [23] considered different nanoparticles with volume fractions in the range 0 to $3 \%$. They showed that thermal conductivity enhancement is proportional to the volume fraction but independent of temperature. 
Several investigations on the use of nanofluids in solar thermal energy systems have been conducted, as seen in recent reviews by Verma and Tiwari [24] and Kasaeian et al. [19]. Most of the studies in these reviews considered the use of nanofluids in non-concentrating solar energy collectors such as flat plate solar collectors, evacuated tube collectors and direct absorption concentrating collectors. Recently, the number of investigations on the utilisation of nanofluids for high-temperature concentrating solar energy systems is increasing. For example, Waghole et al. [25] presented a study on the use of silver nanofluids together with twisted tape inserts to enhance the heat transfer performance of a receiver tube of a parabolic trough solar energy system. Sokhansefat et al. [26] considered the use of a synthetic oil- $\mathrm{Al}_{2} \mathrm{O}_{3}$ nanofluid in the receiver tube of a parabolic trough solar energy collector. In a study by Taylor et al. [27], it was shown that using nanofluids, the performance of a concentrated solar thermal system could be increased in the range 5 to $10 \%$. Mwesigye et al. [28] considered a parabolic trough solar energy system using syltherm800- $\mathrm{Al}_{2} \mathrm{O}_{3}$ nanofluid as a heat transfer fluid. The thermal efficiency increased up to $7.6 \%$. The thermodynamic performance was also shown to improve for some range of flow rates. In another study, Mwesigye et al. [29], used Cu-Therminol® VP-1 nanofluid to improve the performance a parabolic trough solar energy system with a geometrical concentration ratio of 113 . The thermal efficiency improved by up to $12.5 \%$. Bellos et al.[30] investigated the improvement in receiver thermal performance using nanofluids and convergingdiverging absorber tube of a parabolic trough solar energy system. The use of nanofluids was shown to increase collector efficiency by $4.25 \%$. Amina Benabderrahmane et al.[31] presented a three dimensional numerical investigation of the heat transfer of a parabolic trough receiver having longitudinal fins and nanofluids with a $1 \%$ volume fraction. The thermal performance was shown to increase with heat transfer enhancement. Chen et al.[32] considered the effect of using silver based nanofluids in a direct absorption solar energy collector. The collector efficiency was shown to increase with nanoparticle volume fraction and then reaches a maximum value.

From the above literature review, there is growing unanimity that the heat transfer enhancement of receiver tubes of parabolic trough solar energy systems is crucial in improving overall system performance and reducing the temperature gradients in the receiver's absorber tube, thereby increasing the reliability of the system. Besides, the additional benefits of improved 
thermodynamic performance make the heat transfer enhancement of parabolic trough receivers attractive. Only a few of the reviewed studies, have considered the potential improvements in the thermodynamic performance of the receiver with heat transfer enhancement. As can be expected, reduced absorber tube temperatures will lead to improved thermodynamic performance. Therefore, a comparative thermal and thermodynamic performance analysis and optimisation of a parabolic trough system utilising three types of nanofluids for a system with a high geometrical concentration ratio was investigated in this study. These nanofluids were copper-Therminol ${ }^{\circledR} \mathrm{VP}$ 1, silver-Therminol ${ }^{\circledR} \mathrm{VP}-1$ and $\mathrm{Al}_{2} \mathrm{O}_{3}$-Therminol ${ }^{\circledR} \mathrm{VP}-1$. In addition, the performance improvement potential at various concentration ratios was investigated and presented. Unlike other studies, the thermal and thermodynamic performance of the parabolic trough system is optimised in this study. Moreover, the emissivity of the absorber tube's selective coating is taken to be temperature dependent to accurately predict the improvement in thermal and thermodynamic performance of the receiver. In the thermal performance analysis, the improvement in the system's energetic performance is determined using the thermal efficiency and heat transfer coefficients while the entropy generation minimisation method is used for the purpose of thermodynamic optimisation to determine the conditions with the lowest exergy destruction.

\section{Physical model}

The schematic diagram of the parabolic trough solar energy system under consideration is shown in Fig. 1. It is essentially made of a collector that receives the incoming solar radiation, focusing it onto a receiver tube located at the focus of the parabolic collector. As shown in the figure, for a system with a perfect mirror surface, all the rays parallel to the focal line of the collector are reflected to its focal point at which the receiver tube is placed. It is clear in this arrangement that the lower half of the receiver tube will receive concentrated solar heat flux, while the upper half of the receiver receives only direct solar radiation. It is this non-uniformity of the heat flux distribution that results in temperature gradients in the receiver tube. Among other things, the magnitude of these temperature gradients will depend on a number of factors, such as the collector's geometry, the optical errors within in the system, the flow rate of the heat transfer fluid, the heat transfer fluid properties and the magnitude of the incident solar radiation. 
The receiver tube is central to the entire system's performance. As such, its state significantly influences the thermal performance of the entire system. To improve the receiver's performance, several means of reducing the receiver's thermal loss are incorporated during its manufacture. Firstly, the receiver's metallic absorber tube is surrounded by a glass envelope and then the annulus space formed is maintained at very low vacuum pressures to suppress the natural convection heat loss. Typical vacuum pressure in the annulus space is about $0.013 \mathrm{~Pa}$ [8]. Another means of reducing receiver thermal loss is the selective coating of the absorber tube, which makes it highly absorptive of the incoming solar radiation and with low emission of outgoing infrared radiation. Furthermore, getter material is used to prevent an accumulation of hydrogen in the annulus space, since its presence increases receiver thermal losses and degrades its thermal performance [33,34]. To account for differential thermal expansion between the absorber tube and the glass cover, metal bellows are used at both ends of the receiver. Figure 2(a) gives a schematic representation of the receiver tube. A cross-section view of the receiver tube (excluding the metal bellows and glass to metal seals) is shown in Fig. 2(b).

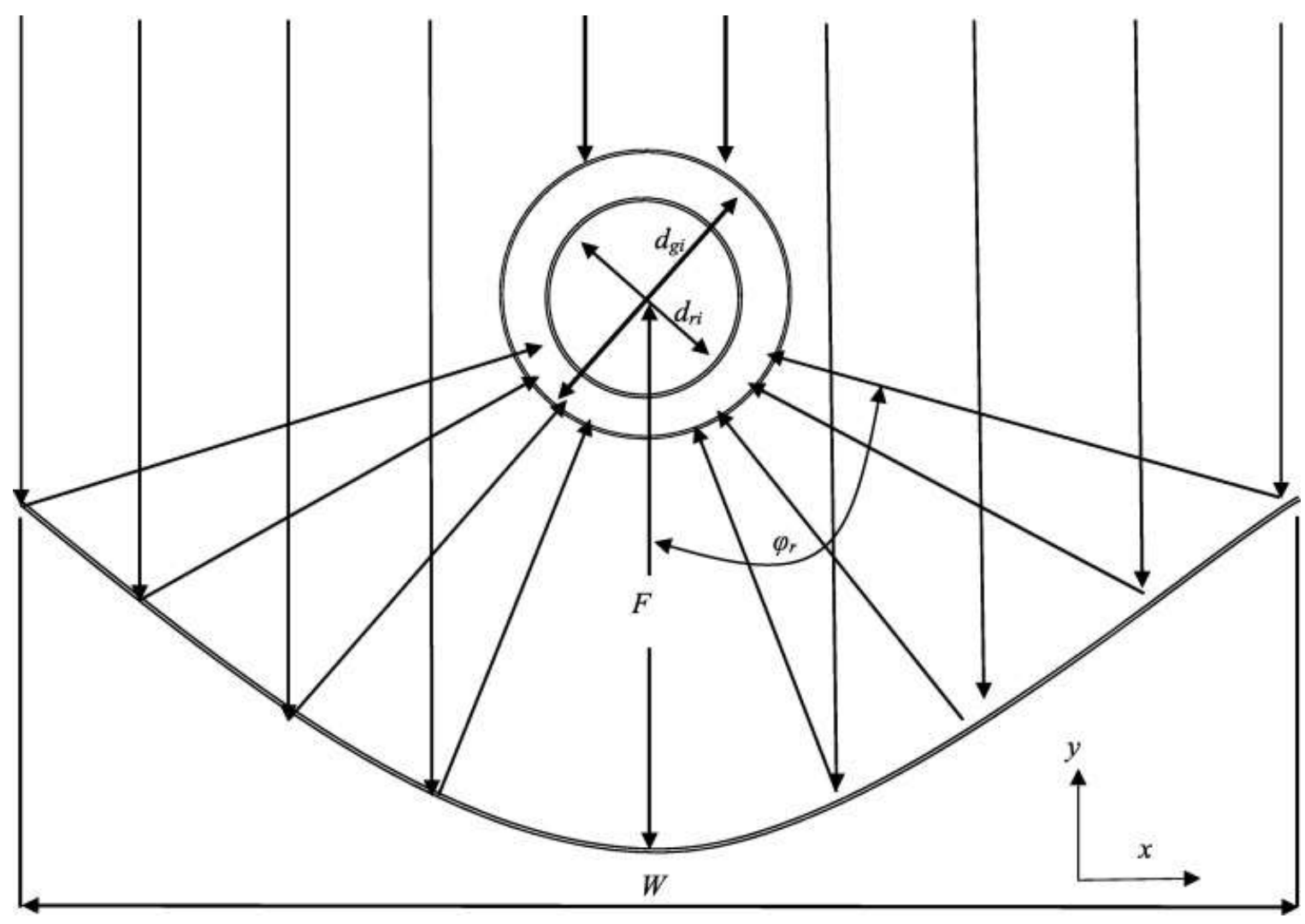

Fig. 1. A cross-section view of a parabolic trough system 


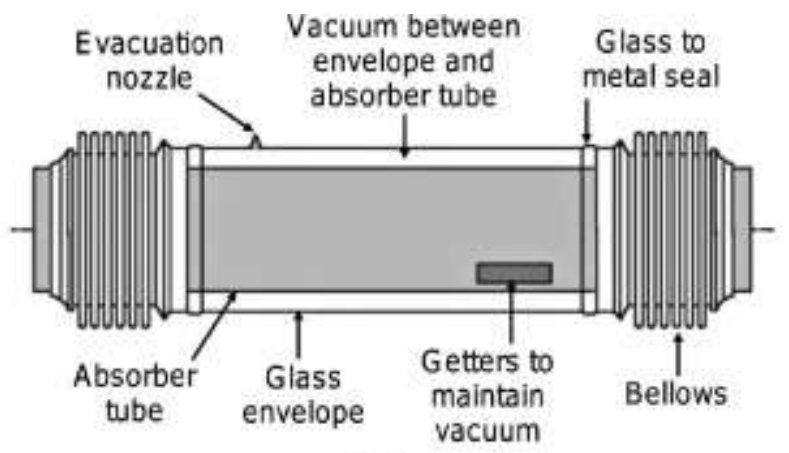

(a)

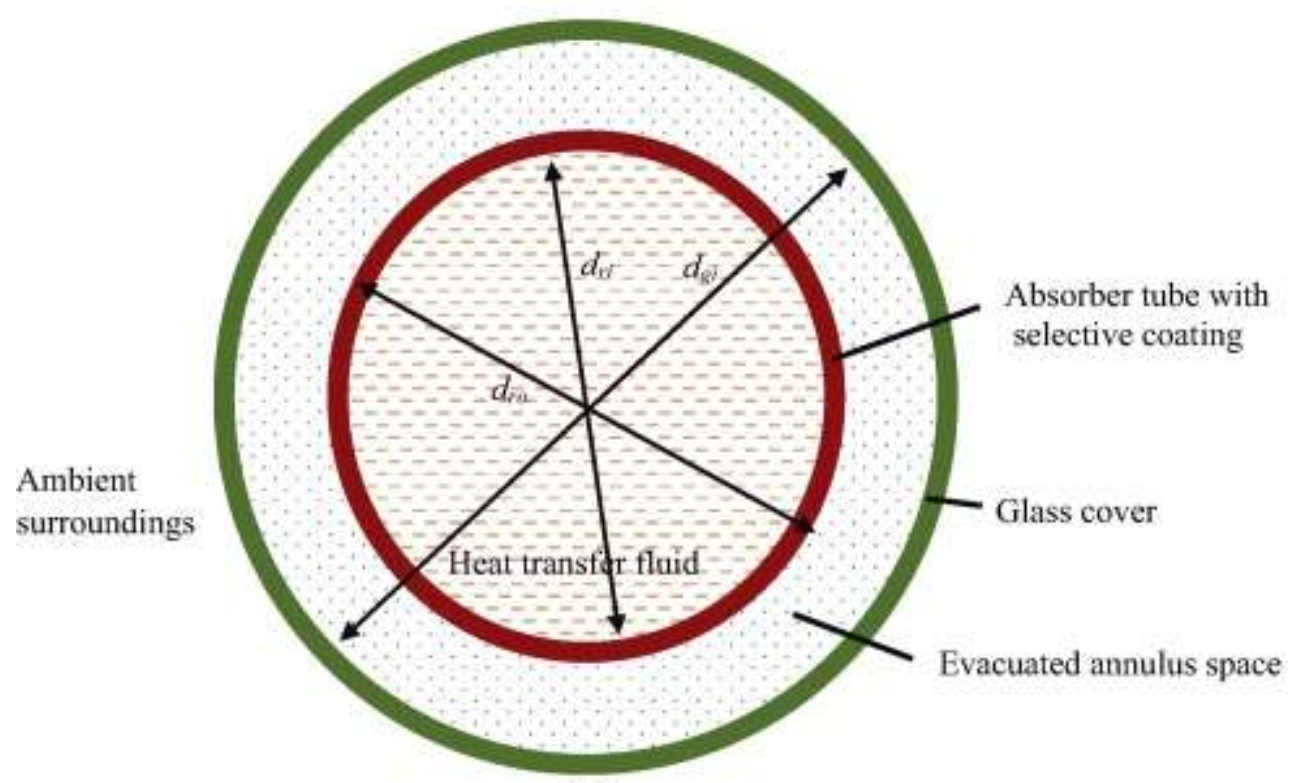

(b)

Fig. 2. (a) Parabolic trough receiver tube [8] , and (b) cross-section of the receiver tube

\section{Theoretical analysis}

\subsection{Optical and thermal analysis}

To get a realistic circumferential heat flux distribution on the receiver's absorber tube, a precise representation of the geometry of the parabolic trough solar energy system is required. The collector aperture, collector rim angle and collector focal length are some of the important parameters that are needed. The profile of the collector is given by the equation of a parabola [35] as follows:

$x^{2}=4 F y$ 
Equation (1) is consistent with the Cartesian coordinate system shown in Fig. 1. The parabola's focal length $(F)$ gives the location of the receiver tube. It is given by [35] as follows:

$$
F=\frac{W}{4 \tan \left(\varphi_{r} / 2\right)}
$$

where $W$ is the collector aperture width and $\varphi_{r}$ is the collector's rim angle. For a given system with a known collector aperture size and rim angle, the system's focus can therefore be obtained using Eq. (2). The system's concentration ratio is defined in this study as the ratio of the collector's projected area to the projected absorber tube area. According to this definition, the concentration ratio $\left(C_{R}\right)$ is the following:

$$
C_{R}=\frac{W}{d_{r o}}
$$

The thermal performance is given in terms of the useful energy gain, the receiver thermal loss and the thermal efficiency. The useful energy delivered to the user is given by the following equation:

$\dot{Q}_{u}=\dot{m} c_{p}\left(T_{\text {out }}-T_{\text {in }}\right)$

where $\dot{m}$ is the mass flow rate, $c_{p}$ is the specific heat capacity of the heat transfer fluid, $T_{\text {out }}$ is the heat transfer fluid outlet temperature and $T_{i n}$ is the absorber tube inlet temperature. The useful energy can also be obtained from

$\dot{Q}_{u}=I_{b} \eta_{o} A_{a}-\dot{Q}_{\text {loss }}=I_{b} \eta_{o} A_{a}-A_{r o} U_{L}\left(T_{r o}-T_{a}\right)$

In Eq. (5), $I_{b}$ is the direct normal irradiance, $A_{a}$ is the unshaded aperture area, $A_{r o}$ is the absorber tube outer wall surface area, $\eta_{o}$ is the optical efficiency, $\dot{Q}_{\text {loss }}$ are the receiver thermal losses, $U_{L}$ is the overall heat transfer coefficient for thermal losses between the absorber tube outer wall at a temperature $T_{r o}$ and the ambient surroundings at a temperature $T_{a}$. In this study, the receiver thermal loss is obtainable directly from the developed computational fluid dynamics model.

For a receiver tube having an evacuated annulus space, the natural convection losses are suppressed. The free molecular convection heat transfer at these low pressures is also much lower than the radiation heat transfer and can be neglected [36]. As such, the receiver thermal loss can be determined as follows: 


$$
\dot{Q}_{\text {loss }}=\frac{\pi d_{r o} L \sigma\left(T_{r o}^{4}-T_{g i}^{4}\right)}{\frac{1}{\varepsilon_{r o}}+\frac{1-\varepsilon_{g}}{\varepsilon_{g}}\left(\frac{d_{r o}}{d_{g i}}\right)}
$$

In Eq. (6), $L$ is the length of the system, $\sigma$ is Stefan Boltzmann constant, $\varepsilon$ is the emissivity and $d$ is the diameter. The subscripts $r o$ and $g i$ represent the absorber tube outer wall and the glass cover inner wall, respectively. From the energy balance on the receiver, it is clear that the thermal loss between the absorber tube and the glass cover is equal to the energy transfer by conduction through the glass cover and is equal to the energy transfer by convection and radiation from the glass cover to the surroundings. For the rate of energy transfer to the surroundings, receiver the thermal loss can be written as follows:

$$
\dot{Q}_{\text {loss }}=\pi d_{g o} L h_{w}\left(T_{g o}-T_{a}\right)+\varepsilon_{g} \pi d_{g o} L \sigma\left(T_{g o}^{4}-T_{s k y}^{4}\right)
$$

In which, $h_{w}$ is the convection heat transfer coefficient between the outer wall of the glass cover and the ambient surroundings and the subscripts go represents the glass cover outer wall. An equation for the conduction heat transfer through the glass cover can also be written, giving the same values as Eqs. (6) and (7).

The convection heat transfer coefficient $\left(h_{w}\right)$ in Eq. (7) is a function of the wind velocity $\left(V_{w}\right)$ and the diameter of the outer glass cover. It can be determined using a correlation by Mullick and Nanda [37] as follows:

$$
h_{w}=V_{w}^{0.58} d_{g o}^{-0.42}
$$

The sky temperature is related to the ambient temperature according to [38] as follows:

$T_{s k y}=0.0552 T_{a}^{1.5}$

In terms of the absorber tube's selective coating, the emissivity depends on the absorber tube's temperature. For the PTR70 receiver, the emissivity is given by Burkholder and Kutscher [39] as:

$$
\varepsilon_{r o}=0.062+2 \times 10^{-7}\left(T_{r o}-273.15\right)^{2}
$$

In this form, $T_{r o}$ is the temperature in Kelvin. Equation (10) results in an emissivity of about 0.094 when the temperature is $673.15 \mathrm{~K}\left(400{ }^{\circ} \mathrm{C}\right)$.

With the above relations, the thermal efficiency is usually obtained using Eq. (11) 
$\eta_{t h}=\frac{\dot{Q}_{u}}{I_{b} A_{a}}$

In cases where it becomes essential to include the influence of pumping power, Eq. (11) is modified and written as follows [40] :

$\eta_{t h}=\frac{\dot{Q}_{u}-\dot{W}_{p} / \eta_{e l}}{I_{b} A_{a}}$

With Eq. (12), it is possible to account for the reduction in the thermal efficiency as the pumping power increases. This is likely to occur when the absorber tube's diameter is reduced [40] or with heat transfer enhancement, such as the use of absorber tube inserts, absorber tube surface modifications or the use of nanofluids [29,41]. In Eq. (12), the electrical efficiency $\left(\eta_{e l}\right)$ of the

power block was $32.7 \%$ similar to Wirtz et al. [40] and the pumping power $\left(\dot{W}_{p}\right)$ is the product of the flow rate and the pressure drop as $\dot{W}_{p}=\dot{V} \Delta P$.

\subsection{Thermodynamic analysis}

In section 3.1, the equations relating to the receiver's thermal performance are mostly based on the first law of thermodynamics, which gives the quantity of energy after energy balances are performed. It is always important to understand the quality of energy from any given system, firstly to identify any irreversibilities present in the system and later on to minimise these irreversibilities. The entropy generation minimisation method has emerged as an important tool that uses the second law of thermodynamics to thermodynamically optimise thermal energy systems and system components. With the knowledge of entropy generation rates, the exergetic performance of the system can be determined since exergy destruction is related to the entropy generation rates according to $T_{o} S_{g e n}$, in which $T_{o}$ is the dead state temperature and $S_{g e n}$ is the entropy generation rate [42]. For convective heat transfer, Bejan [42] gave an analytical solution of the entropy generation rates due to heat transfer and fluid flow as follows:

$$
S_{\text {gen }}^{\prime}=\frac{q^{\prime 2}}{\pi \lambda T_{b u l k}^{2} N u}+\frac{32 \dot{m}^{3} c_{f}}{\pi^{2} \rho^{2} T_{b u l k} D^{5}}
$$

In this equation, the first term represents the heat transfer irreversibility, the second term gives the fluid friction irreversibility. $\dot{m}$ is the mass flow rate, $D$ is the tube diameter, $q^{\prime}$ is the heat 
transfer rate per unit length, $N u=h D / \lambda$ with $h=q^{\prime \prime} /\left(T_{w}-T_{b u l k}\right), c_{f}=(-d p / d x) \rho D / 2 G^{2}$, with $G=4 \dot{m} / \pi D^{2}$ and $T_{\text {bulk }}$ is the bulk fluid temperature $\left(T_{\text {in }}+T_{\text {out }}\right) / 2$.

It has been shown that Eq. (13) works well with simple boundary conditions such as a constant heat flux on the tube and for cases where the flow features do not depart significantly from simple pipe flow [43-45]. When complex boundary conditions exist, entropy generation rates obtained locally for each control volume are more precise [43,44]. With this method, the entropy generation rates are determined for each control volume, and these rates are later integrated over the entire computational domain. The total entropy generation rate is a summation of the fluid friction irreversibility and the heat transfer irreversibility. The volumetric fluid friction irreversibility is obtained according to Kock and Herwig [43,44] as follows:

$$
\left(S_{\text {gen }}^{\prime \prime \prime}\right)_{F}=\frac{\mu}{\bar{T}}\left(\frac{\partial \bar{u}_{i}}{\partial x_{j}}+\frac{\partial \bar{u}_{j}}{\partial x_{i}}\right) \frac{\partial \bar{u}_{i}}{\partial x_{j}}+\frac{\rho \varepsilon}{\bar{T}}
$$

Equation (14) is made up of two parts. The first part represents the entropy due to direct dissipation (laminar part) and the second part represents the entropy due to turbulent dissipation. The volumetric heat transfer irreversibility is given by Kock and Herwig $[43,44]$ as follows:

$$
\left(S_{\text {gen }}^{\prime \prime \prime}\right)_{H}=\frac{\lambda}{\bar{T}^{2}}(\nabla \bar{T})^{2}+\frac{\alpha_{t}}{\alpha} \frac{\lambda}{\bar{T}^{2}}(\nabla \bar{T})^{2}
$$

Equation (15) also consists of the same respective parts as Eq. (14). In these equations, $\mu$ is the fluid's dynamic viscosity, $\rho$ is the fluid's density, $\varepsilon$ is the turbulence dissipation rate, $\lambda$ is the fluid's thermal conductivity and $\alpha$ and $\alpha_{t}$ in the last part represent the thermal diffusivities.

Equations (14) and (15) are for the entropy generation rates for an individual control volume. To determine the entropy generation rates over the entire domain, the total volumetric entropy generation rate $\left(S_{g e n}^{\prime \prime \prime}\right)$ which is the summation of Eqs. (14) and (15) is integrated over the entire volume of the fluid under consideration. Accordingly, the total entropy generation rate becomes the following:

$$
S_{g e n}=\iiint_{V} S_{g e n}^{\prime \prime \prime} d V
$$




\section{Numerical analysis}

The theoretical analysis approach of obtaining the thermal performance of parabolic trough solar energy systems assumes uniform temperature distribution on the absorber tube of the receiver. In practice, this is not the case, since the receiver has a non-uniform heat flux distribution given that most of the reflected rays will hit the absorber tube's lower half (see Fig. 1). To precisely represent the heat flux distribution and determine its influence on the receiver's thermal and thermodynamic performance of the receiver, the combined use of computational fluid dynamics and Monte Carlo ray tracing has proved to be a vital approach $[15,29,45]$. This approach is discussed in this section.

\subsection{Ray tracing}

It is essential that the actual distribution of heat flux on the absorber tube's outer wall circumference is determined and used in the numerical investigation of the performance of the parabolic trough solar energy system. An open-source ray tracing tool, SolTrace [46], was used for this purpose. Equations (1) and (2) were used to specify the parabolic trough system's geometry. For each of the concentration ratios used and a rim angle of $80^{\circ}$, the focal length will vary according to Eq. (2). For concentration ratios of 88, 100 and 113, the collector aperture widths were $7 \mathrm{~m}, 8 \mathrm{~m}$ and $9 \mathrm{~m}$, respectively. For the receiver tube, an absorber tube diameter of $0.080 \mathrm{~m}$ and an outer glass cover diameter of $0.12 \mathrm{~m}$ were used throughout this study. The parabolic trough solar energy system was considered to be $5 \mathrm{~m}$ in length. The optical properties specified were the absorptivity of the absorber tube taken as 0.96 , the reflectivity of the collector mirror taken as 0.97 , the transmissivity of the glass cover taken as 0.97 . The optical properties of the receiver used are similar to those of the $4^{\text {th }}$ generation Schott solar PTR ${ }^{\circledR} 70$ receivers [47]. The collector slope error taken as $3 \mathrm{mrad}$ and the collector mirror's specularity error was taken as $0.5 \mathrm{mrad}$. The chosen slope and specularity error values are in line with those in commercial systems as shown in an optical measurement study by Wendelin [48].

During ray tracing, $1 \times 10^{8}$ rays were used as the number of sun-generated rays and traced as they went through various optical interactions. For the desired number of ray intersections, $1 \times 10^{6}$ was used. These settings gave a very accurate representation of the expected heat flux profile on the absorber tube's outer wall. The results were in very good agreement with those of other studies. The validation of this study's ray tracing results and receiver thermal model is presented in 
Section 7.2. At the different concentration ratios used, the heat flux distribution obtained for a system with a rim angle of $80^{\circ}$, a collector slope error of $3 \mathrm{mrad}$ and a mirror specularity error of $0.5 \mathrm{mrad}$ are shown in Fig. 3. As expected and similar to most studies in literature, heat flux distribution is non-uniform along the absorber tube's circumference and uniform along the absorber tube's length. The heat flux is shown to increase with the increasing concentration ratio, especially for $\theta<30^{\circ}$. Moreover, the heat flux on the top most half of the absorber tube i.e. $\theta>$ $30^{\circ}$ is almost the same at all the rim angle. This half always receives mostly the direct normal solar irradiance from the sun irrespective of the concentration ratio. The heat flux distribution on the absorber tube is symmetrical about the $y$-axis. Therefore, the heat flux distribution on the $90^{\circ}$ $\leq \theta \leq 270^{\circ}$ half is the same as that on the $-90^{\circ} \leq \theta \leq 90^{\circ}$ half of the absorber tube shown.

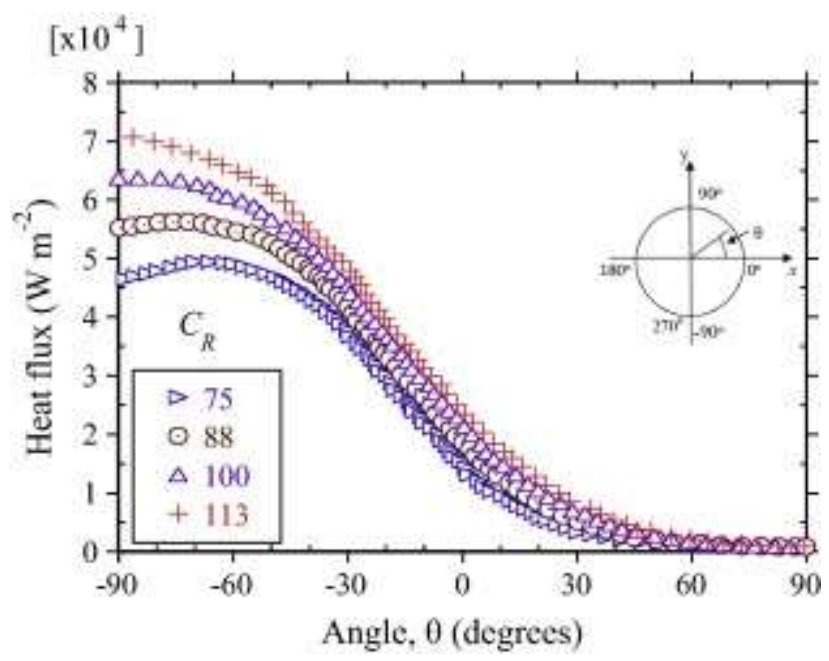

Fig. 3. Circumferential heat flux distribution on the absorber tube's outer wall for different concentration ratios with a rim angle of $80^{\circ}$, a collector slope error of $3 \mathrm{mrad}$ and a mirror specularity error of $0.5 \mathrm{mrad}$

\subsection{Governing equations}

Flow rates in the receiver tubes of parabolic trough solar energy systems are usually turbulent for better thermal performance and the subsequent reduction of the temperature gradients in the receiver. In this study, the flow is considered three-dimensional, steady-state and turbulent. For this type of flow, the governing equations are the continuity, Reynolds averaged Navier-Stokes, and the averaged energy equations [49]. 
Continuity

$\frac{\partial\left(\rho \bar{u}_{i}\right)}{\partial x_{i}}=0$

Momentum equation

$$
\frac{\partial}{\partial x_{j}}\left(\rho \bar{u}_{i} \bar{u}_{j}\right)=-\frac{\partial \bar{P}}{\partial x_{i}}+\frac{\partial}{\partial x_{j}}\left[\mu\left(\frac{\partial \bar{u}_{i}}{\partial x_{j}}+\frac{\partial \bar{u}_{j}}{\partial x_{i}}\right)-\frac{2}{3} \mu \frac{\partial \bar{u}_{i}}{\partial x_{i}} \delta_{i j}-\rho \overline{u_{i}^{\prime} u_{j}^{\prime}}\right]
$$

Energy equation

$$
\frac{\partial}{\partial x_{j}}\left(\rho \bar{u}_{j} c_{p} \bar{T}\right)=\frac{\partial}{\partial x_{j}}\left(\lambda \frac{\partial \bar{T}}{\partial x_{j}}+\frac{\mu_{t}}{\sigma_{h, t}} \frac{\partial\left(c_{P} \bar{T}\right)}{\partial x_{j}}\right)+\bar{u}_{j} \frac{\partial \bar{P}}{\partial x_{j}}+\left[\mu\left(\frac{\partial \bar{u}_{i}}{\partial x_{j}}+\frac{\partial \bar{u}_{j}}{\partial x_{i}}\right)-\frac{2}{3} \mu \frac{\partial \bar{u}_{i}}{\partial x_{i}} \delta_{i j}-\rho \bar{u}_{i}^{\prime} u_{j}^{\prime}\right] \frac{\partial \bar{u}_{i}}{\partial x_{j}}
$$

The averaging process results in Reynolds stresses appearing in Eqs. (18) and (19). The Reynolds stress can be obtained according to [49] as follows:

$$
\overline{-\rho u_{i}^{\prime} u_{j}^{\prime}}=\mu_{t}\left(\frac{\partial \bar{u}_{i}}{\partial x_{j}}+\frac{\partial \bar{u}_{j}}{\partial x_{i}}\right)-\frac{2}{3}\left(\rho k+\mu_{t} \frac{\partial \bar{u}_{k}}{\partial x_{k}}\right) \delta_{i j}
$$

Where $k$ is the turbulence kinetic energy determined according to [49] as:

$$
k=\frac{1}{2}\left(\overline{u^{\prime 2}}+\overline{v^{\prime 2}}+\overline{w^{\prime 2}}\right)
$$

Another result of the averaging process is the closure problem. This requires more equations so that the number of unknown variables equals the number of known variables. For this study, the realisable $k-\varepsilon$ model was implemented for turbulence closure [50]. This model is an improvement of the widely used and validated standard $k-\varepsilon$ model. It requires two additional equations, one for the turbulent kinetic energy $(k)$ and another one for the turbulent dissipation rate $(\varepsilon)$.

Turbulent kinetic energy is obtained using the following equation [49,50]: 


$$
\frac{\partial}{\partial x_{j}}\left(\rho k \bar{u}_{j}\right)=\frac{\partial}{\partial x_{j}}\left[\left(\mu+\frac{\mu_{t}}{\sigma_{k}}\right) \frac{\partial k}{\partial x_{j}}\right]+G_{k}-\rho \varepsilon
$$

while, the turbulent dissipation rate $(\varepsilon)$ can be obtained according to $[49,50]$ as follows

$$
\frac{\partial}{\partial x_{j}}\left(\rho \varepsilon \bar{u}_{j}\right)=\frac{\partial}{\partial x_{j}}\left[\left(\mu+\frac{\mu_{t}}{\sigma_{\varepsilon}}\right) \frac{\partial \varepsilon}{\partial x_{j}}\right]+\rho C_{1} S \varepsilon-\rho C_{2} \frac{\varepsilon^{2}}{k+\sqrt{v \varepsilon}}
$$

In Eq. (23), $G_{k}$ represents the production of turbulent kinetic energy and is determined from

$$
G_{k}=-\rho \overline{u_{i}^{\prime} u_{j}^{\prime}} \frac{\partial \bar{u}_{j}}{\partial x_{i}}
$$

where

$$
G_{k}=\mu_{t} S^{2}
$$

with the eddy viscosity determined according to [49]

$$
\mu_{t}=\rho C_{\mu} \frac{k^{2}}{\varepsilon}
$$

A detailed explanation of the realisable $k-\varepsilon$ model and information on the determination of $C_{\mu}$ is given in the ANSYS ${ }^{\circledR}$ theory guide [49]. The constants for the realisable $k$ - $\varepsilon$ model are given as follows:

$$
C_{1}=\max \left[0.43, \frac{\eta}{\eta+5}\right], \eta=S \frac{k}{\varepsilon}, S \equiv \sqrt{2 S_{i j} S_{i j}}, C_{2}=1.9, \sigma_{k}=1, \sigma_{\varepsilon}=1.2
$$

and $S_{i j}$ is the rate of linear deformation of a fluid element.

\subsection{Boundary conditions}

Figure 4 depicts the computational domain used in this study. 


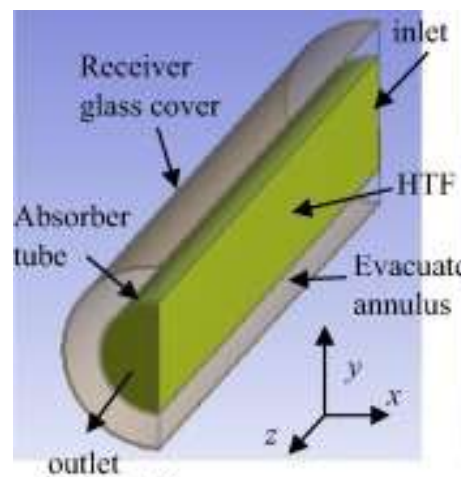

(a)

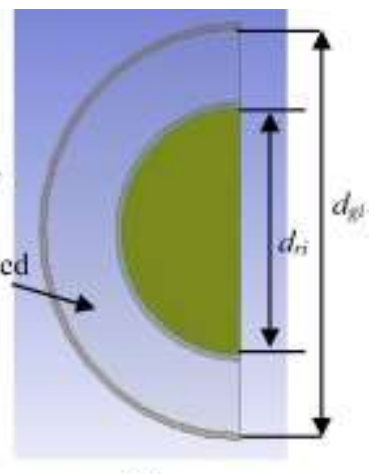

(b)

Fig. 4. Computational domain used (a) lateral view of the receiver, and (b) cross-section view of the receiver

From Figs. (2), (3) and (4) and for a system with a length, $L$, the boundary conditions necessary to attain the numerical solution of the thermal and thermodynamic performance include the following:

i. A non-uniform heat flux profile is specified on the circumference of the outer wall of the receiver's absorber tube. The profile used is a polynomial expression that represents the flux shown in Fig. 3, depending on the concentration ratio under consideration. At a given concentration ratio, each heat flux profile was hooked to the numerical model in the computational fluid dynamics tool using user-defined functions.

ii. At the inlet of absorber tube, a uniform velocity and a given inlet temperature were specified.

iii. At the outlet of the absorber tube, a pressure outlet boundary condition was specified.

iv. All receiver walls (absorber tube and glass cover) were modelled with the no-slip and nopenetration boundary conditions.

v. Given the symmetrical nature of problem, only half of the receiver was considered as shown in the computational domain in Fig. 4.

vi. Considering the low pressures in the annulus space and the fact that no flow occurs, only radiation heat transfer is the most significant heat transfer mechanism. A symmetry boundary condition was therefore specified for the receiver annulus inlet and outlet. This gives zero values of normal gradients for all flow variables at the inlet and outlet of the annulus space. 
vii. The radiation and convection heat transfer from the receiver's glass cover were accounted for using a mixed convection and radiation boundary condition on the outer wall of the receiver's glass cover. Radiation heat transfer between the glass cover and the sky was modelled using Stefan Boltzmann's law for a specified sky temperature while convection heat transfer from the receiver's glass cover to the ambient surroundings was modelled using a specified a convective heat transfer coefficient and a free stream temperature. The sky temperature is a function of the ambient temperature and was determined using Eq. (9). An ambient temperature of $300 \mathrm{~K}$ was used throughout the study. The convection heat transfer coefficient at the receiver's glass cover was obtained using Eq. (8). The wind speed, which is represented by $V_{w}$ in Eq. (8) was considered to be perpendicular to the axis of the receiver, and a value of $2 \mathrm{~m} \mathrm{~s}^{-1}$ was used.

The other geometrical, environmental, optical properties and flow parameters used are given in Table 1. In this investigation, the concentration ratio is defined according to Eq. (3) given in Section 3.1 .

Table 1. Geometrical, optical, environmental and flow parameters

\begin{tabular}{lc}
\hline \multicolumn{1}{c}{ Parameter } & Value \\
\hline Inner diameter of the absorber tube, $d_{r i}(\mathrm{~m})$ & 0.076 \\
Outer diameter of the absorber tube, $d_{r o}(\mathrm{~m})$ & 0.080 \\
Inner diameter or the receiver, $d_{g i}(\mathrm{~m})$ & 0.120 \\
Collector aperture widths, $W(\mathrm{~m})$ & $7.0,8.0,9.0$ \\
Length, $L(\mathrm{~m})$ & 5.0 \\
Inlet temperatures, $T_{\text {in }}(\mathrm{K})$ & $400-650$ \\
Flow rate $\left(\mathrm{m}^{3} \mathrm{~h}^{-1}\right)$ & $1.22-134.73$ \\
Direct normal irradiance, $I_{b}\left(\mathrm{~W}\right.$ m $\left.{ }^{-2}\right)$ & $88,100,113$ \\
Geometrical concentration ratios, $C_{R}$ & $80^{\circ}$ \\
Rim angle, $\varphi_{r}$ & 0.96 \\
Absorptivity of the selective coating, $\alpha_{a b s}$ & 0.97 \\
Reflectivity of the collector mirror, $\rho$ & 0.97 \\
Transmissivity of the receiver's glass cover, $\tau_{g}$ & $3 \mathrm{mrad}$ \\
Collector slope error, $\sigma_{\text {slope }}$ & $0.5 \mathrm{mrad}$ \\
Mirror specularity error, $\sigma_{\text {spec }}$ & \\
\hline
\end{tabular}




\subsection{Material properties}

\subsubsection{Base fluid thermophysical properties}

To get the most precise results as possible, it is essential that the thermophysical properties are accurate representations of the properties of the materials used. In this study, the commonly used commercial heat transfer fluid, Therminol ${ }^{\circledR}$ VP-1[51], was used as the base fluid. For this heat transfer fluid, temperature dependent thermophysical properties were used. The manufacturer's technical data sheets [51] were used to obtain the relations representing the thermophysical properties using regression analysis. The specific heat capacity, density and thermal conductivity of Therminol ${ }^{\circledR}$ VP-1 are given by Eqs. (28) - (30), respectively and the viscosity is given by Eqs. (31) and (32).

For $285.15 \mathrm{~K} \leq T \leq 698.15 \mathrm{~K}$,

$$
\begin{aligned}
& c_{p}=2.125 \times 10^{3}-11.017 T+0.049862 T^{2}-7.7663 \times 10^{-5} T^{3}+4.394 \times 10^{-8} T^{4}\left(\mathrm{~J} \mathrm{~kg}^{-1} \mathrm{~K}^{-1}\right) \\
& \rho=1.4386 \times 10^{3}-1.8711 T+2.737 \times 10^{-3} T^{2}-2.3793 \times 10^{-6} T^{3}\left(\mathrm{~kg} \mathrm{~m}^{-3}\right) \\
& \lambda=0.14644+2.0353 \times 10^{-5} T-1.9367 \times 10^{-7} T^{2}+1.0614 \times 10^{-11} T^{3}\left(\mathrm{~W} \mathrm{~m}^{-1} \mathrm{~K}^{-1}\right)
\end{aligned}
$$

Piecewise polynomials given by Eqs. (31) and (32) were used for the viscosity of Therminol®VP-1.

For $285.15 \mathrm{~K} \leq T \leq 373.15 \mathrm{~K}$,

$$
\mu=3.661 \times 10^{2}-3.0154 T+8.3409 \times 10^{-3} T^{2}-7.723 \times 10^{-6} T^{3}(\mathrm{mPa} \mathrm{s})
$$

For $373.15 \mathrm{~K} \leq T \leq 698.15 \mathrm{~K}$,

$$
\mu=23.165-0.1476 T+3.617 \times 10^{-4} T^{2}-3.9844 \times 10^{-7} T^{3}+1.6543 \times 10^{-10} T^{4}(\mathrm{mPa} \mathrm{s})
$$

\subsubsection{Nanoparticle thermophysical properties}

Three types of nanoparticles were considered and suspended in the base fluid in an attempt to investigate improvements in the thermal and thermodynamic performance of the parabolic 
trough solar collector. The considered nanoparticles were the commonly used $\mathrm{Al}_{2} \mathrm{O}_{3}$ metallic oxide, as well as copper and silver metallic nanoparticles, which have significantly higher thermal conductivities compared to that of $\mathrm{Al}_{2} \mathrm{O}_{3}$.

Similar to the properties of the base fluid, the thermophysical properties of all the nanoparticles were also considered to vary with temperature. The polynomials giving these properties were determined from property information obtainable from the appendices of Incropera et al.[52].

For Aluminum oxide $\left(\mathrm{Al}_{2} \mathrm{O}_{3}\right)$ nanoparticles, a density of $3970 \mathrm{~kg} \mathrm{~m}^{-3}$ [52] was used. At a temperature $T$, the thermal conductivity is determined from the following equation [52]:

$$
\lambda=148.14-0.56883 T+9.794 \times 10^{-4} T^{2}-8.0417 \times 10^{-7} T^{3}+2.5595 \times 10^{-10} T^{4}\left(\mathrm{~W} \mathrm{~m}^{-1} \mathrm{~K}^{-1}\right)
$$

The specific heat capacity of $\mathrm{Al}_{2} \mathrm{O}_{3}$ is obtainable from the following equation [52]:

$$
c_{p}=-531.43+7.135 T-0.011923 T^{2}+9.3125 \times 10^{-6} T^{3}-2.7679 \times 10^{-9} T^{4}\left(\mathrm{~J} \mathrm{~kg}^{-1} \mathrm{~K}^{-1}\right)
$$

For copper nanoparticles, a density of $8933 \mathrm{~kg} \mathrm{~m}^{-3}$ [52] was used. At a temperature $T$, the thermal conductivity of the copper nanoparticles is given by the following equation [52]

$$
\lambda=441.6-0.17119 T+1.5446 \times 10^{-4} T^{2}-7.2917 \times 10^{-8} T^{3}\left(\mathrm{~W} \mathrm{~m}^{-1} \mathrm{~K}^{-1}\right)
$$

The specific heat capacity of copper nanoparticles is obtainable from the following equation [52]

$$
c_{p}=285.8+0.44631 T-5.2054 \times 10^{-4} T^{2}+2.3958 \times 10^{-7} T^{3}\left(\mathrm{~J} \mathrm{~kg}^{-1} \mathrm{~K}^{-1}\right)
$$

For silver nanoparticles, a density of $10500 \mathrm{~kg} \mathrm{~m}^{-3}$ [52] was used. At a temperature $T$, the thermal conductivity of silver nanoparticles is given by the following equation [52]

$$
\lambda=420.29+0.10383 T-3.1536 \times 10^{-4} T^{2}+2.4167 \times 10^{-7} T^{3}-7.1429 \times 10^{-11} T^{4}\left(\mathrm{~W} \mathrm{~m}^{-1} \mathrm{~K}^{-1}\right)
$$

The specific heat capacity of silver nanoparticles is obtainable from the following equation [52]

$$
c_{p}=2244-0.1195 T+4.1083 \times 10^{-4} T^{2}-4.25 \times 10^{-7} T^{3}+1.6667 \times 10^{-10} T^{4}\left(\mathrm{~J} \mathrm{~kg}^{-1} \mathrm{~K}^{-1}\right)
$$

Table 2 shows the sample properties of the nanoparticles considered at the temperatures of 400 $\mathrm{K}, 600 \mathrm{~K}$ and $800 \mathrm{~K}$. 
Table 2. Sample properties of the different nanoparticles at different temperatures

\begin{tabular}{lllcc}
\hline \multirow{2}{*}{ Thermal property } & & \multicolumn{3}{c}{ Temperature (K) } \\
& & $400 \mathrm{~K}$ & $600 \mathrm{~K}$ & $800 \mathrm{~K}$ \\
\hline Specific heat capacity $\left(c_{p}\right), \mathrm{J} \mathrm{kg}^{-1} \mathrm{~K}^{-1}$ & $\mathrm{Cu}:$ & 397 & 417 & 433 \\
& $\mathrm{Ag}:$ & 239 & 250 & 262 \\
& $\mathrm{Al}_{2} \mathrm{O}_{3}:$ & 940 & 1110 & 1180 \\
\hline Thermal conductivity $(\lambda), \mathrm{W} \mathrm{m}^{-1} \mathrm{~K}^{-1}$ & $\mathrm{Cu}:$ & 393 & 379 & 366 \\
& $\mathrm{Ag}:$ & 425 & 412 & 396 \\
& $\mathrm{Al}_{2} \mathrm{O}_{3}:$ & 32.4 & 18.9 & 13 \\
\hline
\end{tabular}

\subsubsection{Nanofluid thermophysical properties}

A number of approaches can be used to determine the properties of nanofluids. Moreover, the properties of the resulting Therminol@VP-1 - nanoparticle mixture will considerably depend on the properties of the different elements of the mixture. In this work, a single-phase modelling approach was used to model the nanofluids resulting from combining Therminol@VP-1 with the different nanoparticles considered in this study. This approach was deemed sufficient, since all the nanofluids will be based on the same equations. Moreover, this approach has been shown to give reasonably accurate results when the volume fractions of the nanoparticles in the base fluid are low (less than 10\%) and when the nanoparticles have smaller diameters (less than $100 \mathrm{~nm}$ ) [53,54]. In this approach, the properties of the resulting nanofluids were determined using the commonly used equations available in literature. The density of the resulting nanofluid was obtained using the classical formula for conventional solid-liquid mixtures $[55,56]$.

$\rho_{n f}=(1-\phi) \rho_{b}+\phi \rho_{p}$

In which, the subscript $n f$ represents nanofluids and $p$ represents nanoparticle. The nanofluid specific heat capacity was obtained using an expression that is derived assuming thermal equilibrium between particles and the neighbouring liquid according to the following equation [55,56]:

$c_{p_{n f}}=\frac{(1-\phi) c_{p_{b}} \rho_{b}+\phi c_{p p} \rho_{p}}{(1-\phi) \rho_{b}+\phi \rho_{p}}$

The viscosity was obtained using the following equation [56,57]: 


$$
\mu_{n f}=\mu_{b}\left(123 \phi^{2}+7.3 \phi+1\right)
$$

This equation was preferred since it was shown to predict the viscosity better than the commonly used Einstein's model for viscosity, which underestimates the viscosity.

The Bruggeman model [58] was used for nanofluid thermal conductivity. It is valid over an extensive range of volume fractions. It gives the thermal conductivity as follows [58]:

$$
\lambda_{n f}=0.25\left[(3 \phi-1) \lambda_{p}+(2-3 \phi) \lambda_{b}+\sqrt{\Delta}\right]
$$

where

$$
\Delta=\left[(3 \phi-1) \lambda_{p}+(2-3 \phi) \lambda_{b}\right]^{2}+8 \lambda_{p} \lambda_{b}
$$

The Bruggeman model [58] approaches Maxwell's effective medium theory [59] at low volume fractions.

Sedimentation or agglomeration is one of the challenges associated with the use of nanofluids especially as the volume fraction increases. As such, measures should be taken to ensure that the prepared nanofluids remains stable. The use of surfactants has been shown to improve the stability of nanofluids [22, 23]. Moreover, the use of surfactants has been shown to have no influence the thermal conductivity of the nanofluids [22].

The material of the absorber tube was taken as stainless steel $(321 \mathrm{H})$. The thermal conductivity is temperature-dependent as given by Forristall [34]. The absorber tube's selective coating also has a temperature-dependent emissivity given by Eq. (10). The glass cover is of Pyrex ${ }^{\circledR}$ material and its emissivity was specified as 0.86 [34].

\section{Numerical solution procedure}

To determine the system's thermal and thermodynamic performance, a numerical model was developed to solve the governing equations, together with the boundary conditions using the specified material properties. This model was implemented using a commercial computational fluid dynamics software, ANSYS® 16.2 [60]. The computational domain shown in Fig. 4 was developed in ANSYS design modeler and the domain was discretized using the ANSYS meshing tool. Figure 5 depicts the grid used in this study. The grid is mainly hexahedral. Even though no 
flow takes place in the annulus space, a finer mesh was used to ensure good mesh metrics (skewness and orthogonal quality) for better solution convergence.

The numerical solution of the governing equations, together with the boundary conditions, was implemented in ANSYS Fluent [60] using a pressure-based solver, the SIMPLE algorithm for pressure and velocity coupling, second-order upwind schemes to integrate the governing equations and the boundary conditions over the computational domain. The discrete ordinates model was used to model the radiation heat transfer in the receiver's annulus space. Since this is essentially surface-to-surface radiation heat transfer, the air within the annulus space was considered to be non-participating. With this, there is no absorption, emission or scattering of the radiation by the air in the evacuated space as expected.

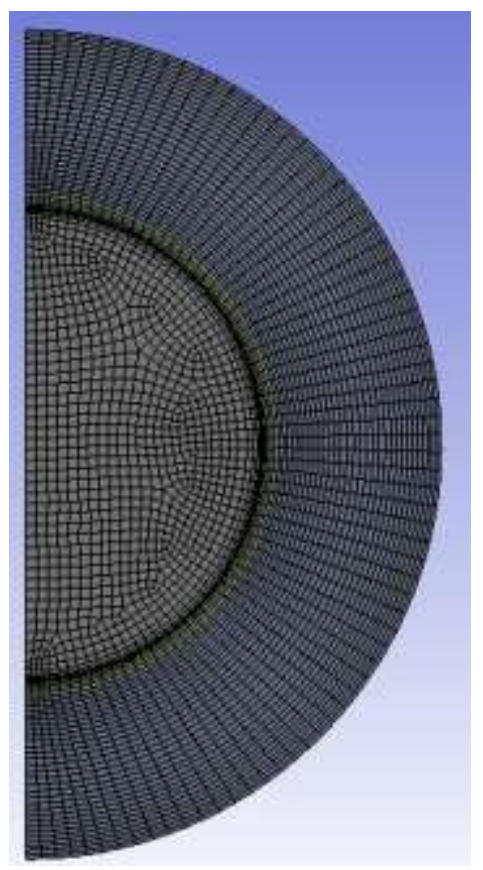

Fig. 5. Cross-section of the sample mesh

The dimensionless wall coordinate $\left(y^{+}\right)$was taken to be lower than 1 throughout this study. The dimensionless wall coordinate was determined from $y^{+}=y u_{\tau} / v$. In this, $v$ is the fluid's kinematic viscosity, $y$ is the distance of the first cell's centroid from the wall and $u_{\tau}$ is the friction velocity. In this near-wall modelling approach, the high resolutions of the gradients in the near-wall region are captured up to the viscous sublayer. With this resolution, the enhanced wall treatment was 
preferred to model the near-wall regions to provide a turbulent model that is valid throughout the near-wall region.

Convergence was monitored in two ways. Firstly, the scaled residuals were set to less than $10^{-4}$ for continuity, less than $10^{-5}$ for momentum, turbulent kinetic energy and turbulent dissipation

rate, and less than $10^{-7}$ for energy. When the scaled residuals of all the quantities were less than the set values, the solution was considered to have converged. In addition, the volume integral of the entropy generation rate and the useful heat transfer rate were used to confirm the solution's convergence. At convergence (scaled residuals less than the ones set), the volume-integrated entropy generation rate $\left(S_{g e n}\right)$ and the useful heat transfer rate had stopped changing for a significant number of iterations. Both quantities ceased changing for over 200 iterations.

\section{Data reduction}

In this section, the parameters used to present this study's results are given. The average heat transfer coefficient $(h)$ was used to show the heat transfer performance. For convective heat transfer from the absorber tube's inner wall to the heat transfer fluid, the heat transfer coefficient is given by the following equation:

$$
h=q^{\prime \prime} /\left(T_{r i}-T_{b u l k}\right)
$$

In Eq. (44), $T_{r i}$ represents the average absorber tube inner wall temperature and $T_{b}$ represents the bulk fluid temperature, which is the average of the inlet and outlet fluid temperatures as $\left(T_{i n}\right.$ $\left.+T_{\text {out }}\right) / 2$.

The Reynolds number is given by the following equation:

$$
\operatorname{Re}=\frac{u_{m} \cdot d_{r i}}{v}
$$

Where, $u_{m}$ is the mean velocity and $v$ is the kinematic viscosity of the heat transfer fluid. The Reynolds number generally depends on the nanofluid volume fraction and the inlet fluid temperature considered at any given flow rate.

Other parameters include the thermal efficiency of the parabolic trough solar energy system given by Eq. (12). As mentioned earlier, this equation accounts for the increase in thermal 
performance less the increase in pumping power, the receiver thermal loss given by Eqs. (6) and (7), the entropy generation rates given by Eqs. (14) - (16). Using Eq. (16), the entropy generation rate per unit length of the receiver is obtained as $S_{g e n}^{\prime}=S_{g e n} / L$, and the Bejan number is defined as $B e=\left(S_{g e n}\right)_{H} /\left(S_{g e n}\right)$, which is defined as the ratio of heat transfer irreversibility to the total entropy generation rate.

\section{Numerical model validation}

\subsection{Grid independence verification}

At a given flow rate, the dimensionless $y^{+}$coordinate lower than 1 was ensured. To achieve this, the distance between the first cell and the wall should be adjusted as the flow rate changes. The distance from the wall had to be reduced as the Reynolds numbers increased, since the more turbulent the flow, the thinner the boundary thickness. Generally, four mesh sizes were considered at representative flow rates, inlet temperatures and volume fractions to determine how the volume-integrated entropy generation rate and the thermal efficiency change as the mesh size and therefore element count changes. The solution was considered mesh independent when the changes in the thermal efficiency and entropy generation rate became less than $1 \%$ as the mesh elements increased due to reduced element size. In this study, the mesh element count was in the range 764235 - 945420 depending on the flow rate and inlet temperature. The higher the Reynolds number, the smaller the distance of the first near-wall cell to give a dimensionless wall coordinate lower than 1 and the more prism layers are used, therefore the higher the mesh count. Table 3 shows the illustration of the grid dependence study using Ag-Therminol@VP-1 nanofluid with the inlet temperature of $650 \mathrm{~K}$, a volume fraction of $4 \%$ and a flow rate of 36.8 $\mathrm{m}^{3} \mathrm{~h}^{-1}$.

Table 3. Sample grid dependence studies for Ag-Therminol®VP-1 nanofluid at a temperature of $650 \mathrm{~K}$ and $\phi=4 \%$, and a flow rate of $36.8 \mathrm{~m}^{3} \mathrm{~h}^{-1}$

\begin{tabular}{lclcc}
\hline $\begin{array}{l}\text { Number } \\
\text { of elements }\end{array}$ & $\begin{array}{l}\text { Thermal } \\
\text { efficiency, } \\
\eta(\%)\end{array}$ & $\begin{array}{l}\text { Entropy generation rate, } \mathrm{S}_{\text {gen }}^{\prime} \\
\left(\mathrm{W} \mathrm{m}^{-1} \mathrm{~K}^{-1}\right)\end{array}$ & Percentage change, $\eta \%$ & $\begin{array}{l}\text { Percentage } \\
\text { change in } \\
S_{\text {gen }}^{\prime} \%\end{array}$ \\
\hline 352620 & 61.01 & 0.2721 & - & - \\
652664 & 62.12 & 0.2616 & 1.82 & 3.86 \\
862650 & 62.90 & 0.2569 & 1.26 & 1.80 \\
1426257 & 62.91 & 0.2561 & 0.02 & 0.31 \\
\hline
\end{tabular}




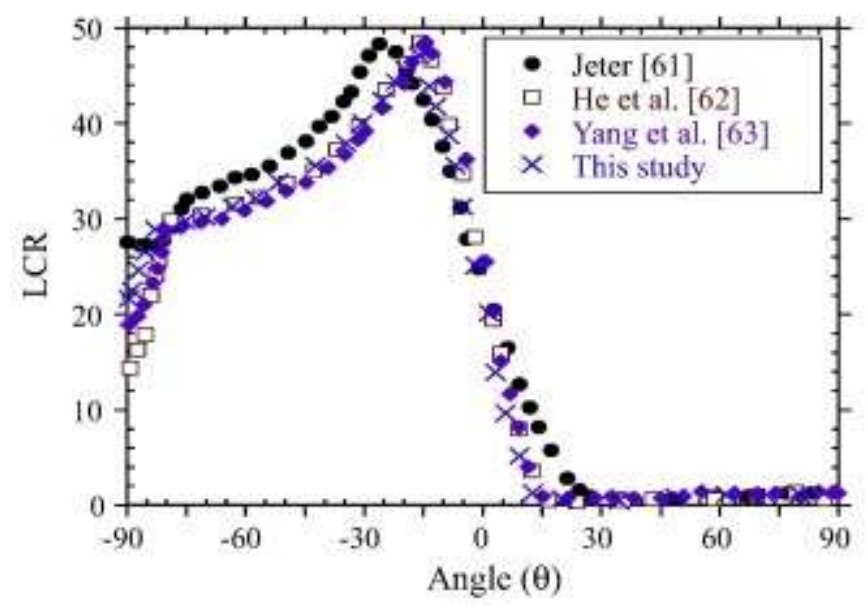

(a)

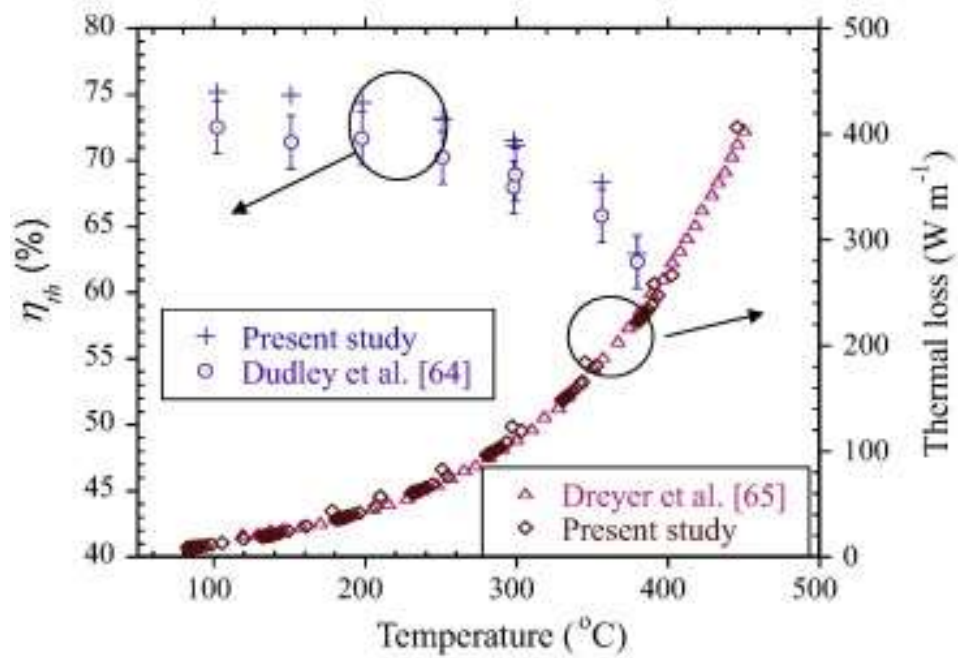

(b)

Fig. 6. Validation of this study's receiver thermal model (a) local concentration ratio using data from Jeter [61], He et al. [62] and Yang et al. [63] and (b) thermal efficiency using data from Dudley et al. [64] and experimental thermal loss using data from Dreyer et al. [65]

\subsection{Numerical model validation}

In this study, to ensure that the model developed is an accurate depiction of a parabolic trough receiver, several steps have been taken to validate results from our study. Firstly, the heat flux distribution on the absorber tube's outer wall, which was determined using Monte Carlo ray tracing, was compared with the results of Jeter [61], He et al. [62] and Yang et al. [63] at comparable geometrical and optical properties. Excellent agreement was obtained, as shown in Fig. 6(a). Secondly, the energetic performance of the developed receiver thermal model was 
validated by comparing the thermal efficiency with the values obtained from the experimental tests conducted on a parabolic trough solar energy system at Sandia national laboratories, presented by Dudley et al. [64] at the same geometrical and environmental parameters. As presented in Dudley et al. [64], the direct normal irradiance, wind speed, ambient temperature, flow rate and inlet temperature at each of the test points was different. A further comparison of the energetic performance of the system was done of this model's receiver thermal loss with experimental data by Dreyer et al. [65] at different temperatures. As shown in Fig. 6 (b), the results of this work compare well with the results of Dudley et al. [64] and Dreyer et al. [65]. This study's results are within $\pm 6 \%$ of the values presented by Dudley et al. [64] and within $\pm 2 \%$ of the values presented by Dreyer et al. [65]. Therefore, the receiver model developed in this work can accurately predict parabolic trough solar energy system's optical and thermal performance over a wide range of parameters.

\section{Results and discussion}

\subsection{Heat transfer performance}

As expected, the suspension of nanoparticles in a base fluid greatly alters its thermal transport properties and results in much-improved thermal performance in comparison to the performance with only the base fluid. As shown in Fig. 7, the heat transfer coefficient increases as the nanoparticle volume fraction increases. In line with findings from other studies, this increase in performance is mainly attributed to the increase in the thermal conductivity of the heat transfer fluid with the suspension of nanoparticles [19]. With the increased thermal conductivity, more energy is transferred by heat from the absorber tube wall to the heat transfer fluid, thus increased useful energy gain from the collector. The heat transfer coefficient will continue to increase with volume fraction provided a sufficient temperature difference between the absorber tube wall and the heat transfer fluid exists. But other limitations such as the stability of the nanofluid and higher pumping power requirements as volume fractions increase will limit the maximum possible volume fraction. The influence of pumping power on overall performance is discussed in section 8.2.

From Fig. 7, it is crucial to note that all the data points correspond to volume flow rates between $1.22 \mathrm{~m}^{3} \mathrm{~h}^{-1}$ and $134.73 \mathrm{~m}^{3} \mathrm{~h}^{-1}$. That is to say, for all volume fractions, all nanofluids and at all inlet temperatures, the flow rates for the successive data points are $1.22 \mathrm{~m}^{3} \mathrm{~h}^{-1}, 4.08 \mathrm{~m}^{3} \mathrm{~h}^{-1}, 12.25$ 
$\mathrm{m}^{3} \mathrm{~h}^{-1}, 20.41 \mathrm{~m}^{3} \mathrm{~h}^{-1}, 28.58 \mathrm{~m}^{3} \mathrm{~h}^{-1}, 36.75 \mathrm{~m}^{3} \mathrm{~h}^{-1}, 44.91 \mathrm{~m}^{3} \mathrm{~h}^{-1}, 53.08 \mathrm{~m}^{3} \mathrm{~h}^{-1}, 61.24 \mathrm{~m}^{3} \mathrm{~h}^{-1}, 69.41 \mathrm{~m}^{3} \mathrm{~h}^{-1}$, $77.57 \mathrm{~m}^{3} \mathrm{~h}^{-1}, 85.74 \mathrm{~m}^{3} \mathrm{~h}^{-1}, 93.90 \mathrm{~m}^{3} \mathrm{~h}^{-1}, 102.07 \mathrm{~m}^{3} \mathrm{~h}^{-1}, 134.73 \mathrm{~m}^{3} \mathrm{~h}^{-1}$, respectively. However, since the thermophysical properties of the base fluid are altered when nanoparticles are added or when temperatures change, the density and viscosity will increase depending on the suspended nanoparticles at a given temperature. Higher density nanoparticles give a nanofluid with a higher density and thus a higher Reynolds number at a given flow rate. For example, at $0 \%$ volume fraction and an inlet temperature of $500 \mathrm{~K}$, the Reynolds number is 471051 when the flow rate is $36.7 \mathrm{~m}^{3} \mathrm{~h}^{-1}$. With nanoparticles, at a volume fraction of $4 \%$ and the same inlet temperature and flow rate, the Reynolds numbers are 360205 with $\mathrm{Al}_{2} \mathrm{O}_{3}$ nanoparticles, 430934 with copper nanoparticles and 453313 with silver nanoparticles. The same trend exists at other temperatures and flow rates.

At the same flow rate, it is observed that using silver nanoparticles gives the highest heat transfer performance, followed by copper nanoparticles, while $\mathrm{Al}_{2} \mathrm{O}_{3}$ nanoparticles gave the lowest performance. This is in line with the thermal conductivities of the nanoparticles used, where silver nanoparticles have the highest thermal conductivity and $\mathrm{Al}_{2} \mathrm{O}_{3}$ nanoparticles have the lowest thermal conductivity at different temperatures (see Table 2). For example, at an inlet temperature of $450 \mathrm{~K}$ and a flow rate of $28.58 \mathrm{~m}^{3} \mathrm{~h}^{-1}$, the heat transfer coefficient is $2248 \mathrm{~W} \mathrm{~m}^{-2}$ $\mathrm{K}^{-1}$ at a volume fraction of $0 \%$. At a volume fraction of $6 \%$, the heat transfer coefficient increases to $2375 \mathrm{~W} \mathrm{~m}^{-2} \mathrm{~K}^{-1}$ for silver-Therminol@VP-1 nanofluid, $2334 \mathrm{~W} \mathrm{~m}^{-2} \mathrm{~K}^{-1}$ for copperTherminol ${ }^{\circledR V P}-1$ nanofluid and $2297 \mathrm{~W} \mathrm{~m}^{-2} \mathrm{~K}^{-1}$ for $\mathrm{Al}_{2} \mathrm{O}_{3}$-Therminol ${ }^{\circledR V P}-1$ nanofluids. This is an increase in the heat transfer coefficient of $5.6 \%, 3.8 \%$ and $2.2 \%$ for silver-Therminol@VP-1, copper-Therminol@VP-1 and $\mathrm{Al}_{2} \mathrm{O}_{3}$-Therminol ${ }^{\circledR V P}-1$ nanofluids, respectively. 


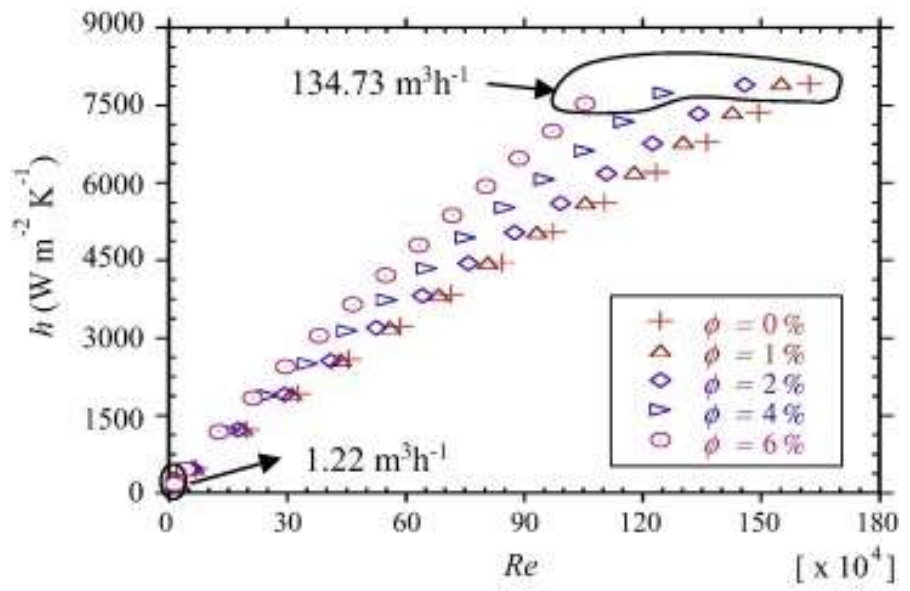

(a)

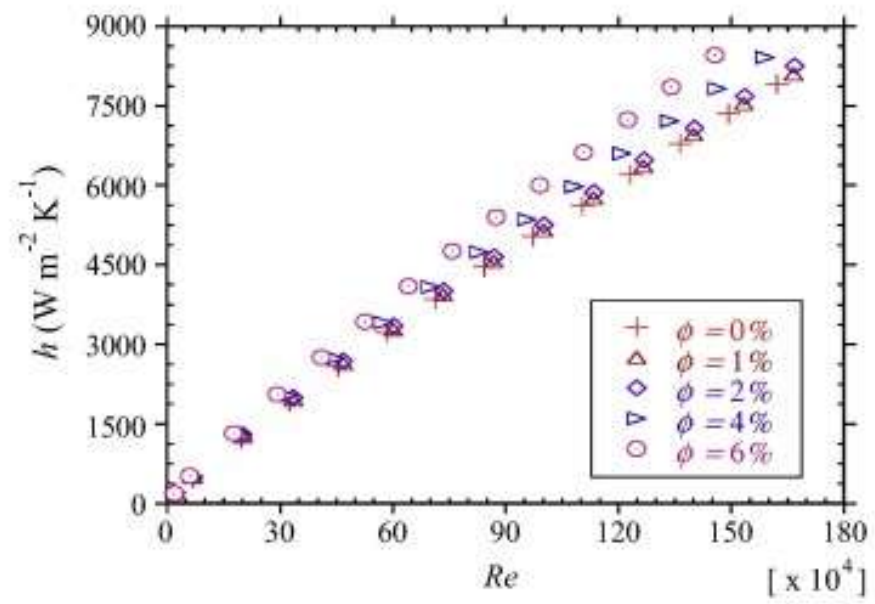

(b)

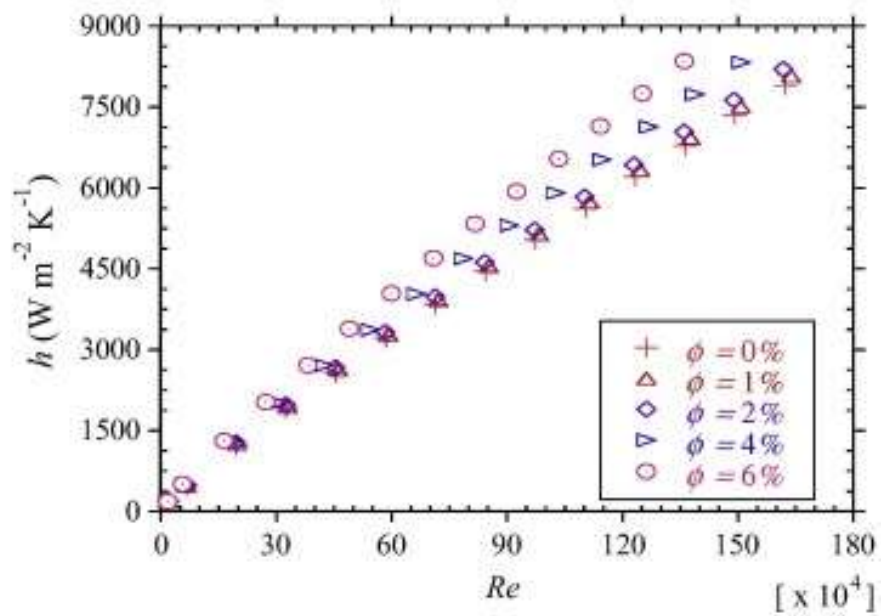

(c)

Fig. 7. Heat transfer coefficient as a function of Reynolds number and nanoparticle volume fraction at an inlet temperature of $550 \mathrm{~K}$ for: (a) $\mathrm{Al}_{2} \mathrm{O}_{3}$-Therminol ${ }^{\circ} \mathrm{VP}-1$, (b) silver-Therminol@VP-1, and (c) copper-Therminol@VP1. 
At an inlet temperature of $600 \mathrm{~K}$ and a flow rate of $36.75 \mathrm{~m}^{3} \mathrm{~h}^{-1}$, the heat transfer coefficient is $3263 \mathrm{~W} \mathrm{~m}^{2} \mathrm{~K}^{-1}$ for a volume fraction of $0 \%$. At a volume fraction of $6 \%$, the heat transfer coefficient increases to $3521 \mathrm{~W} \mathrm{~m}^{-2} \mathrm{~K}^{-1}$ for silver-Therminol®VP-1 nanofluid, $3471 \mathrm{~W} \mathrm{~m}^{-2} \mathrm{~K}^{-1}$ for copper-Therminol®VP-1 nanofluid and $3392 \mathrm{~W} \mathrm{~m} \mathrm{~m}^{-2}$ for $\mathrm{Al}_{2} \mathrm{O}_{3}$-Therminol®VP-1 nanofluids. With this, the increase in heat transfer coefficient is $7.9 \%, 6.4 \%$ and $3.9 \%$ for silverTherminol®VP-1, copper-Therminol®VP-1 and $\mathrm{Al}_{2} \mathrm{O}_{3}$-Therminol®VP-1 nanofluids, respectively. It is also clear from Fig.7 that the heat transfer coefficients increase when the Reynolds number increases. This is due to the improved heat transfer performance with increasing Reynolds numbers due to the thinner thermal boundary layer at high flow rates. It is also evident that to achieve the same heat transfer coefficient as for the high thermal conductivity nanofluid, the flow rate of the low thermal conductivity nanofluid has to be increased.

\subsection{Thermal efficiency}

It is expected that more pumping power will be required to overcome the increase in pressure drop resulting from increased fluid friction with the suspension of the nanoparticles in the base fluid. The pumping power will continually increase with increasing Reynolds numbers and volume fractions, as shown in Mwesigye et al. [29]. In this study, the combined influence of improved heat transfer performance and increased pumping power is shown using the thermal efficiency definition that incorporates the pumping power term given by Eq. (12). With this, both the increase in the useful energy gain with heat transfer enhancement and the accompanying increase in energy consumed by the pump are considered.

Figure 8(a) to (c) depicts the variation of the parabolic trough solar energy system's thermal efficiency with Reynolds number at different nanoparticle the volume fractions for an inlet temperature of $600 \mathrm{~K}$ for $\mathrm{Al}_{2} \mathrm{O}_{3}$-Therminol ${ }^{\circledR} V P-1$, silver-Therminol ${ }^{\circledR V P}-1$, and copperTherminol ${ }^{\circledR}$ VP-1 nanofluids, respectively. As shown, at a given volume fraction, the thermal efficiency rises with increasing Reynolds number, reaches a maximum value and then starts to reduce with a further increase in the Reynolds number. At low Reynolds numbers, the thermal transfer performance is lower and an increase in the flow rate increases the thermal performance with low pumping power requirements. As the Reynolds numbers increase, the pumping power requirement also increases until the increase in pumping power becomes more than the increase in the useful energy delivered, which causes the efficiency to start reducing. 


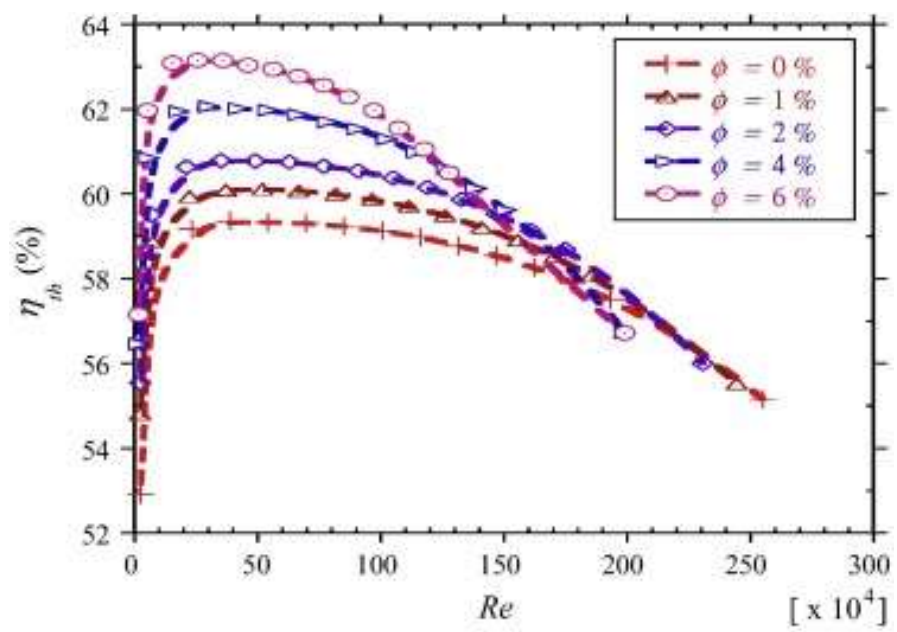

(a)

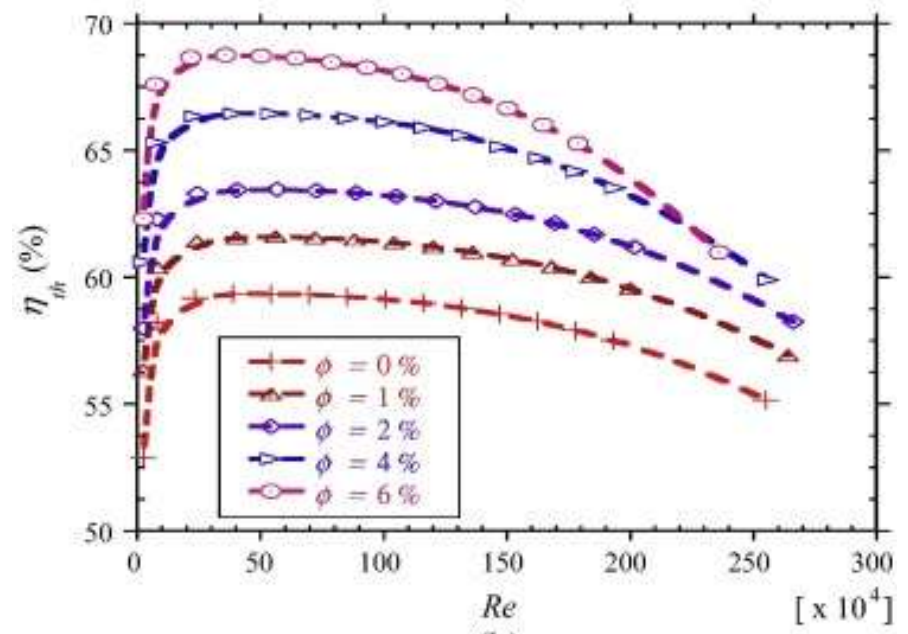

(b)

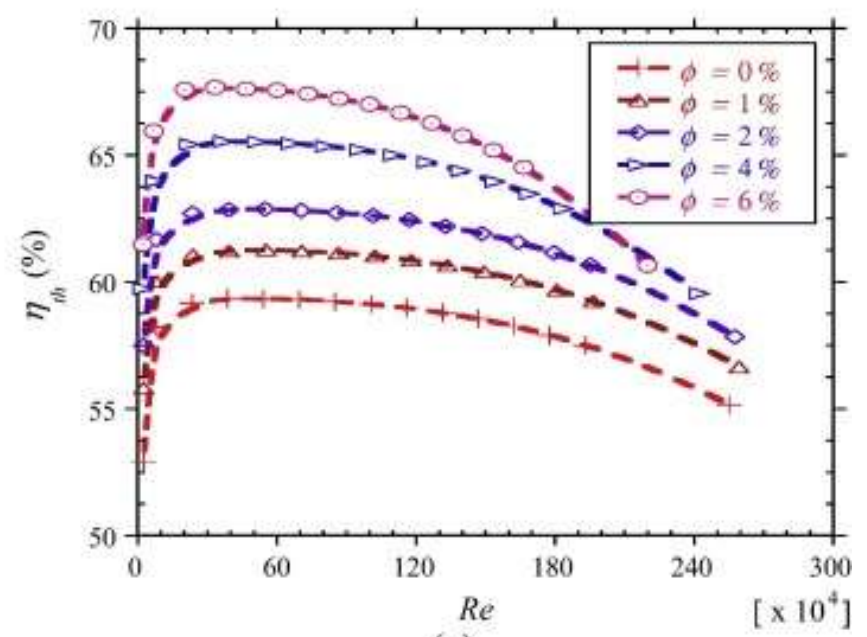

(c)

Fig. 8. Variation of thermal efficiency with nanoparticle volume fraction and Reynolds number at an inlet temperature of $600 \mathrm{~K}$ for (a) $\mathrm{Al}_{2} \mathrm{O}_{3}$-Therminol ${ }^{\circledR} \mathrm{VP}-1$, (b) silver-Therminol ${ }^{\circledR V P}-1$, and (c) copper-Therminol®VP1. 
In this study, the optimal thermal efficiency was found to exist at a flow rate of about $22.5 \mathrm{~m}^{3} \mathrm{~h}^{-1}$ for all inlet temperatures, all volume fractions and all the nanofluids considered. It can also be shown that, the thermal efficiencies do not deviate significantly from the value at the optimum point for flow rates between $20 \mathrm{~m}^{3} \mathrm{~h}^{-1}$ and $40 \mathrm{~m}^{3} \mathrm{~h}^{-1}$. In fact, between these flow rates, the thermal efficiency deviates by less than $0.5 \%$ points from the optimum value.

In some cases, the increase in pumping power is more than the increase in useful energy that is transferred to the user. This makes the thermal efficiency lower than that of a receiver without heat transfer enhancement, reducing its energetic performance. This is shown to exist at temperatures lower than $500 \mathrm{~K}$ and flow rates higher than $60 \mathrm{~m}^{3} \mathrm{~h}^{-1}$ for silver-Therminol®VP-1, and copper-Therminol®VP-1 nanofluids. For $\mathrm{Al}_{2} \mathrm{O}_{3}$-Therminol®VP-1 nanofluid this is shown to exist for almost all temperatures and volume fractions with flow rates higher than $52 \mathrm{~m}^{3} \mathrm{~h}^{-1}$. This can be explained by the fact that the increase in thermal performance was shown to be lower for $\mathrm{Al}_{2} \mathrm{O}_{3}$-Therminol ${ }$ VP-1 nanofluid than for the other types of nanofluids. Given this lower thermal performance increase and the increase in pumping power, the thermal efficiency at high values of volume fraction becomes lower than that at lower volume fractions at high Reynolds numbers.

Figures 9(a) and 9(b) show a plot of the parabolic trough solar energy system's thermal efficiency for the different nanofluids at an inlet temperature of $500 \mathrm{~K}$ and a volume fraction of $4 \%$, as well as an inlet temperature of $600 \mathrm{~K}$ and a volume fraction of $6 \%$, respectively. As already discussed, it is clear that the silver-Therminol ${ }$ VP-1 nanofluid gives the highest increase in thermal efficiency. The increase in thermal efficiency of copper-Therminol®VP-1 nanofluid is almost the same as that of silver-Therminol ${ }^{\circledR V P}-1$, since the thermal conductivities of the two nanoparticles are almost the same. The increase in thermal efficiency with Ag-Therminol®VP-1, copper-Therminol®VP-1 and $\mathrm{Al}_{2} \mathrm{O}_{3}$-Therminol ${ }^{\circledR}$ VP-1 nanofluids were about $13.9 \%, 12.5 \%$ and $7.2 \%$, respectively as the volume fraction increased from 0 to $6 \%$ for the range parameters considered. 


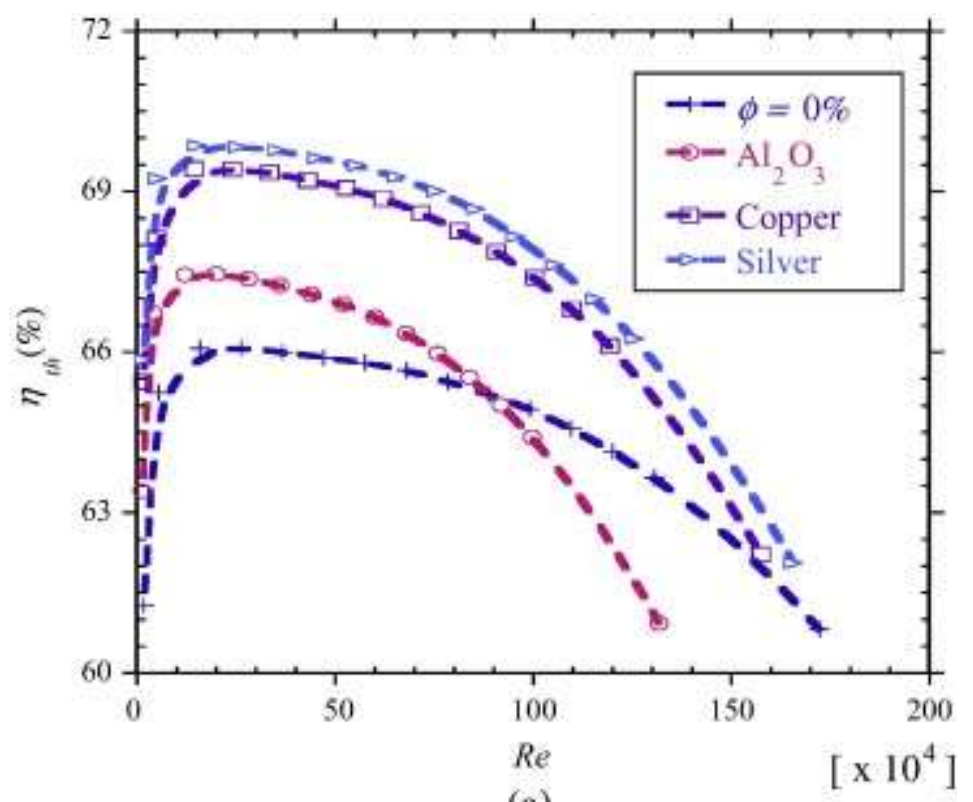

(a)

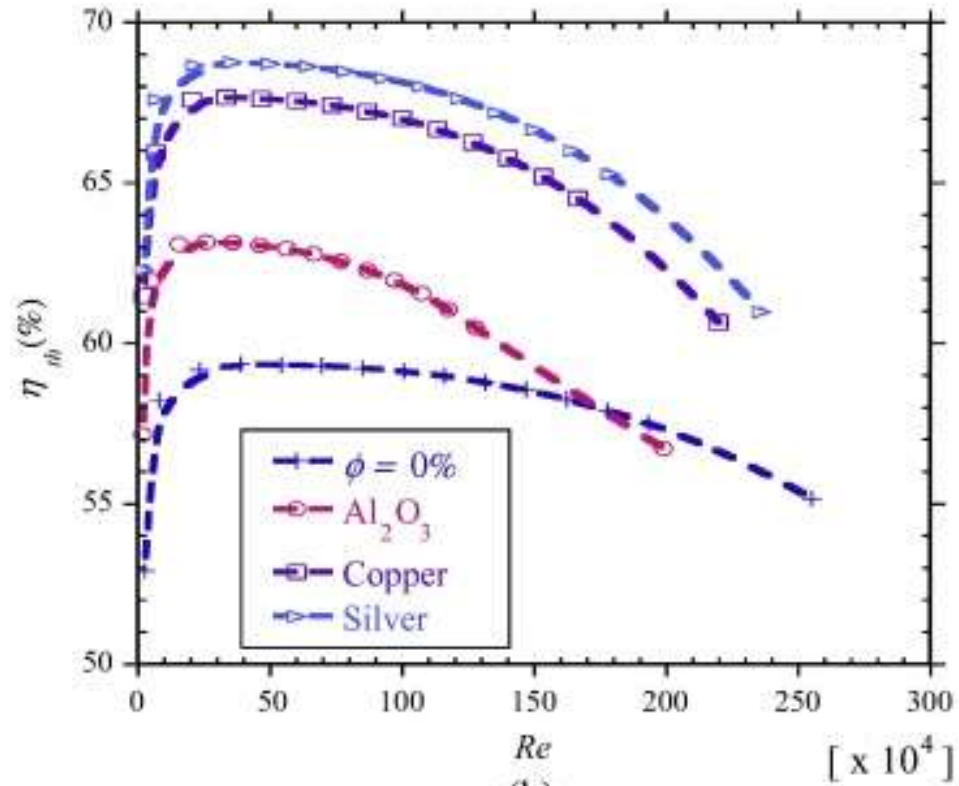

(b)

Fig. 9. Thermal efficiency as a function of the Reynolds number for different nanoparticles at: (a) an inlet temperature of $500 \mathrm{~K}$ and a volume fraction of $4 \%$, and (b) an inlet temperature of $600 \mathrm{~K}$ and a volume fraction of $6 \%$ 

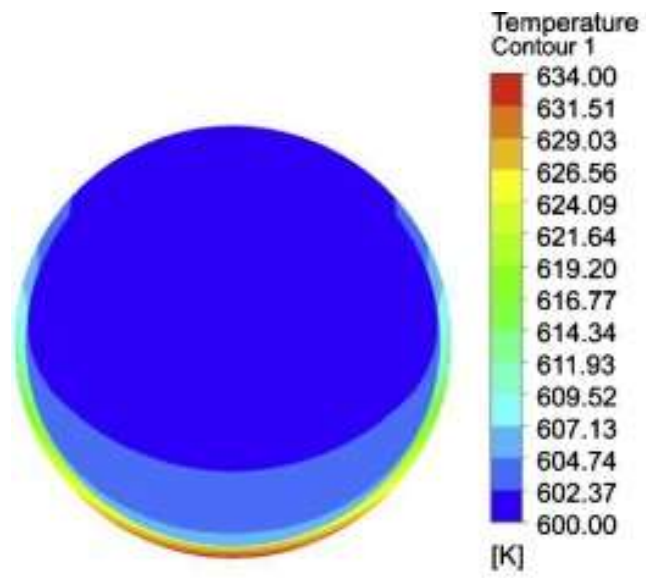

Absorber tube outlet (heat transfer fluid and tube wall)
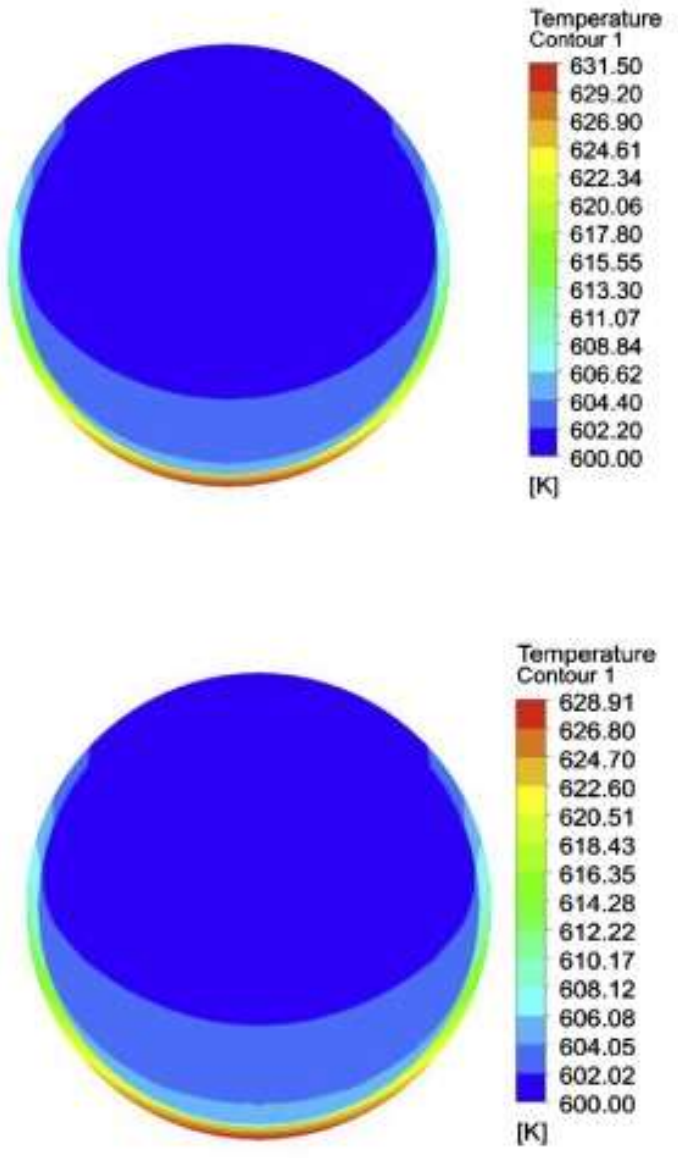

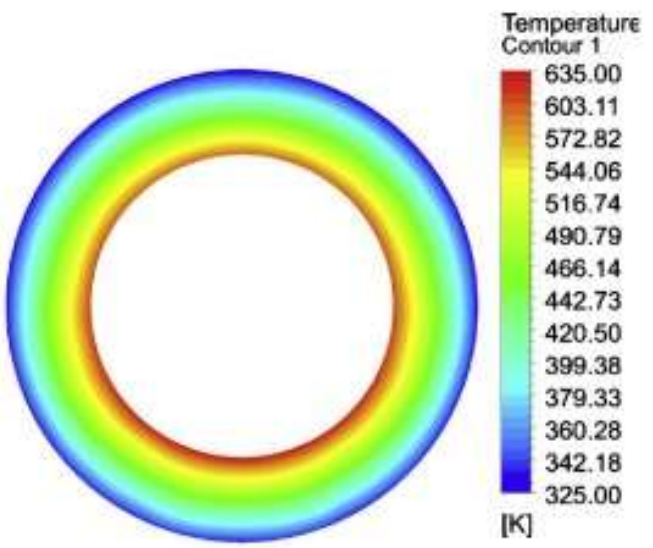

Receiver tube annulus

(a)

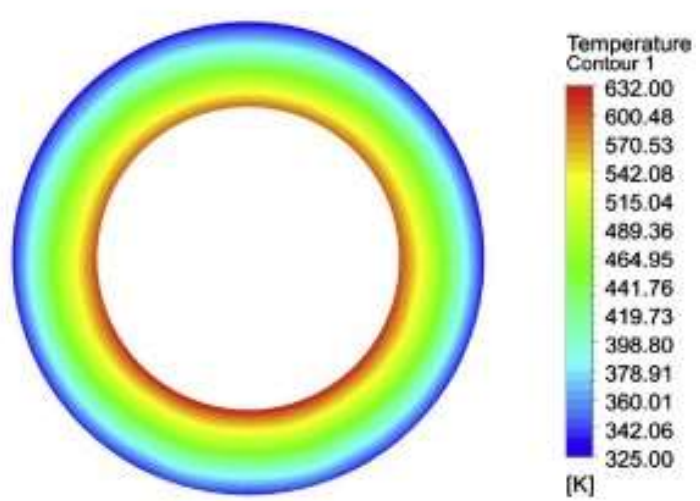

(b)

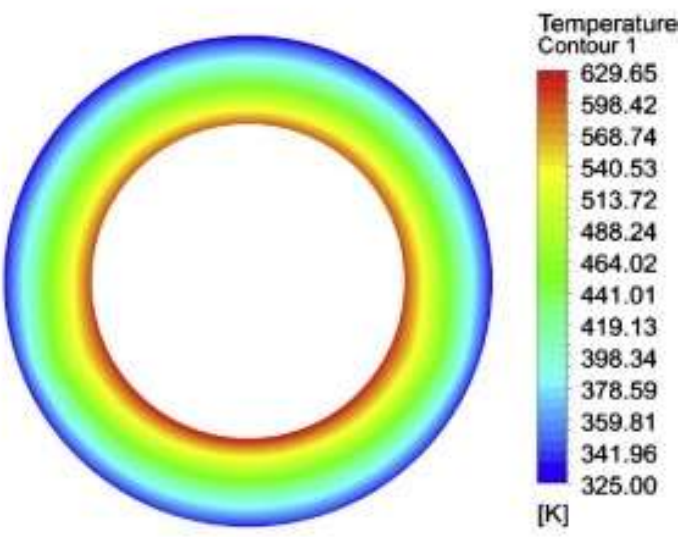

(b)

Fig. 10. Contours of absorber tube and receiver annulus temperatures, respectively at a volumetric flow rate of 36.75 $\mathrm{m}^{3} \mathrm{~h}^{-1}$ and an inlet temperature $600 \mathrm{~K}$ for (a) volume fraction of $0 \%$ (with only the base fluid), (b) volume fraction of $4 \%$ with Ag-Therminol@VP-1 nanofluid and (c) volume fraction of $4 \%$ with $\mathrm{Al}_{2} \mathrm{O}_{3}$-Therminol@VP-1 nanofluid. 
Figure 10 shows the temperature contours of the absorber tube outlet (heat transfer fluid and absorber tube wall) and the receiver's annulus space adjacent to one another at an inlet temperature of $600 \mathrm{~K}$ and a flow rate of $36.75 \mathrm{~m}^{3} \mathrm{~h}^{-1}$ : Fig. 10 (a) without any nanoparticles in the base fluid, Fig. 10 (b) with $\mathrm{Al}_{2} \mathrm{O}_{3}$ nanoparticles at a volume fraction of $4 \%$ and Fig. 10 (c) with silver nanoparticles at a volume fraction of $4 \%$. As shown in these figures, the heat transfer mechanisms are the same and the temperature profiles are what would be expected for a receiver tube with a non-uniform heat flux profile. A closer look at the temperature values shows that there a slight reduction in the maximum absorber tube temperature with the use of nanofluids. The reduction is about $2.5^{\circ} \mathrm{C}$ with $4 \% \mathrm{Al}_{2} \mathrm{O}_{3}$ nanoparticles and $5.09{ }^{\circ} \mathrm{C}$ with silver nanoparticles. Though these are small values, given that temperature is raised to a power of four in the determination of receiver thermal losses, a small reduction in temperature will result in a much higher reduction in the energy transferred by radiation from the absorber tube. Moreover, when the flow rates are lower, significant reductions in absorber tube temperatures can be achieved with heat transfer enhancement [41].

\subsection{Thermodynamic performance}

The thermodynamic performance of thermal energy systems can be characterised and improved by determining the irreversibilities that occur in systems and how these irreversibilities can be minimised [42]. A system with high irreversibilities gives higher entropy generation rates, thus higher rates of destruction of the available energy. To investigate the influence of heat transfer enhancement on receiver thermodynamic performance, the entropy generation rates due to the heat transfer irreversibility and fluid friction irreversibility were determined. As shown in Fig. 11, the entropy generation rate reduces with increasing Reynolds numbers, attains a minimum and increases again as the Reynolds numbers increased further. At values lower than a given Reynolds number, the entropy generation rates reduce as the nanoparticle volume fraction increases. The reduction is shown to be significantly higher for $\mathrm{Al}_{2} \mathrm{O}_{3}$-Therminol®VP-1 nanofluid than for the other nanofluids. This reduction probably occurs due to the lower density of the $\mathrm{Al}_{2} \mathrm{O}_{3}$ nanoparticles, which was taken as $3970 \mathrm{~kg} \mathrm{~m}^{-3}$ compared to $8933 \mathrm{~kg} \mathrm{~m}^{-3}$ and 10 $500 \mathrm{~kg} \mathrm{~m}^{-3}$ for copper and silver nanoparticles, respectively. At low Reynolds numbers, the improvement in heat transfer performance with increasing nanoparticle volume fractions leads to reduced heat transfer irreversibilities. These reduced heat transfer irreversibilities are a result of reductions in the finite temperature difference as the heat transfer performance improves. 
However, with the suspension of nanoparticles in the base fluid, the density of the resulting nanofluid increases, which results in increased pumping power. This increase in pumping power increases the fluid friction irreversibility. As such, the reduction in the heat transfer irreversibility is somehow cancelled with the increased fluid friction irreversibility, which leads to lower reductions in the entropy generation rates as depicted in Fig. 11. At much higher Reynolds numbers, the fluid friction irreversibility is much higher than the heat transfer irreversibility, and the entropy generation rates of the enhanced receiver $(\phi \geq 1 \%)$ become higher than those of a non-enhanced receiver $(\phi=0 \%)$.

In this study, it is shown that the entropy generation rates are reduced by about $24 \%, 19 \%$ and $17 \%$ for $\mathrm{Al}_{2} \mathrm{O}_{3}$-Therminol ${ }^{\circledR V P}-1, \quad$ silver-Therminol ${ }^{\circledR V P}-1$ and copper-Therminol ${ }^{\circledR} \mathrm{VP}-1$ nanofluids, respectively, with Reynolds numbers lower than those for which heat transfer enhancement improves the thermodynamic performance. It is evident from Fig. 11 that for each nanofluid, there is a Reynolds number at a given temperature and nanoparticle volume fraction for which significant reductions in the entropy generation rates are achieved. Beyond that Reynolds number, the entropy generation rate rises greatly with increasing nanoparticle volume fraction and the use of nanofluids does not give improved thermodynamic performance. The figure also shows the existence of a Reynolds number that gives minimum entropy generation rates. Thermodynamically speaking, this would be the preferred Reynolds number since it is the point which the destruction of the available energy is a minimum. However, other considerations such as the required outlet temperature, the effect of flow rates on system design and performance are also important. Nonetheless, any Reynolds number lower than the one that gives minimum entropy generation rates results in better exergetic and energetic performance with heat transfer enhancement. 


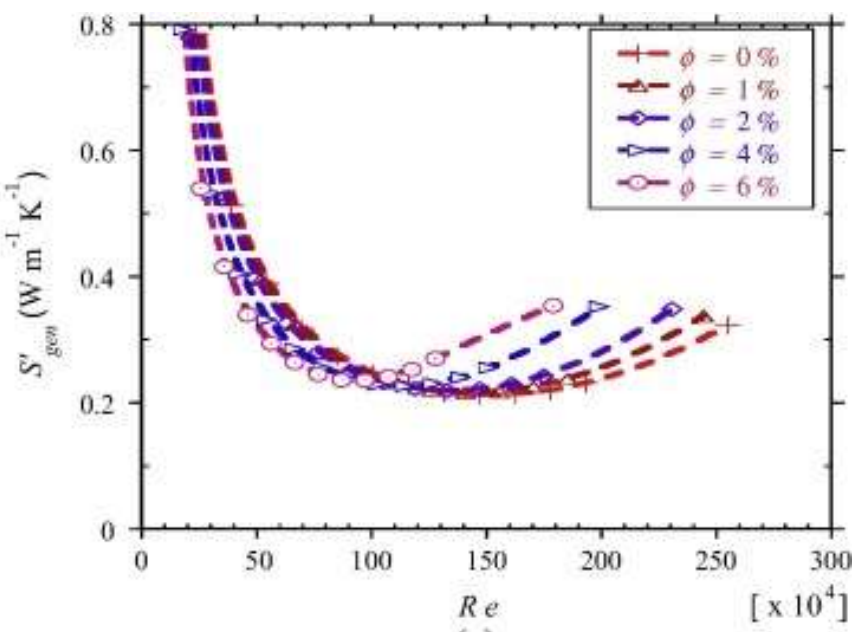

(a)

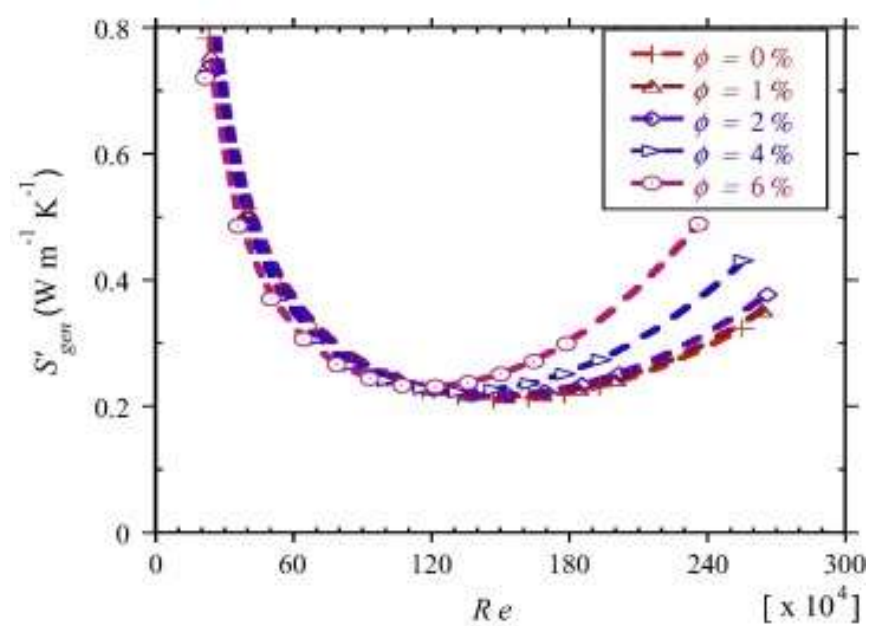

(b)

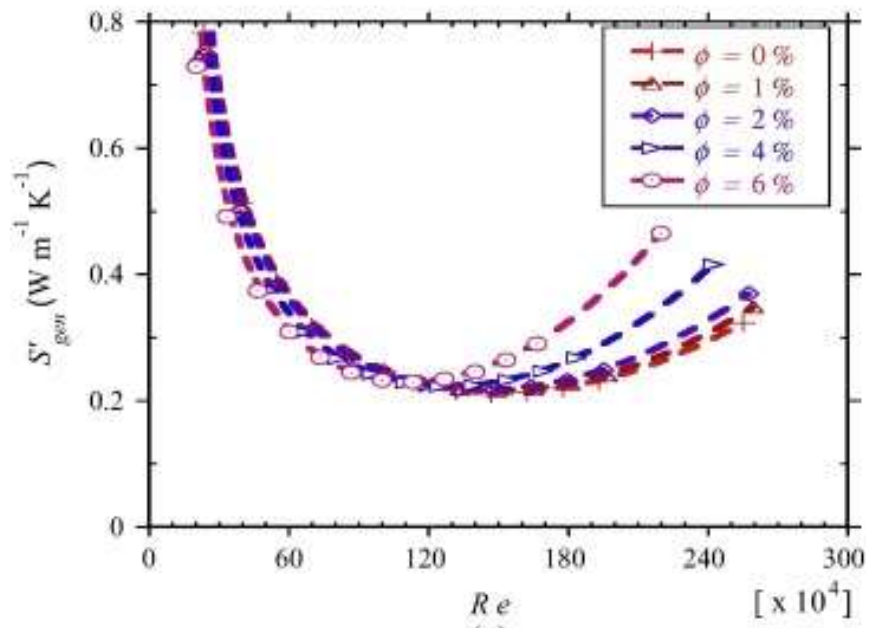

(c)

Fig. 11. Entropy generation rate as a function of nanoparticle volume fraction and Reynolds number at an inlet temperature of $600 \mathrm{~K}$ (a) $\mathrm{Al}_{2} \mathrm{O}_{3}$-Therminol ${ }^{\circledR V P}-1$, (b) copper-Therminol®VP-1 and (c) silver-Therminol ${ }^{\circledR} \mathrm{VP}-1$ 
The Reynolds number under which the thermodynamic performance of the parabolic trough receiver is improved, was obtained for each nanofluid. It was shown that for all the nanofluids, at a given temperature and at all volume fractions, this Reynolds number was almost the same. Figure 12 shows this Reynolds number as a function of nanoparticle volume fraction at different temperatures. This Reynolds number does not to change significantly with volume fraction, but increases with increasing temperature. As temperatures increase, the heat transfer fluid properties change, the density and the viscosity reduce, leading to reduced fluid friction irreversibilities such that slightly higher flow rates can be used before the entropy generation rate becomes greater than the one at $\phi=0 \%$.

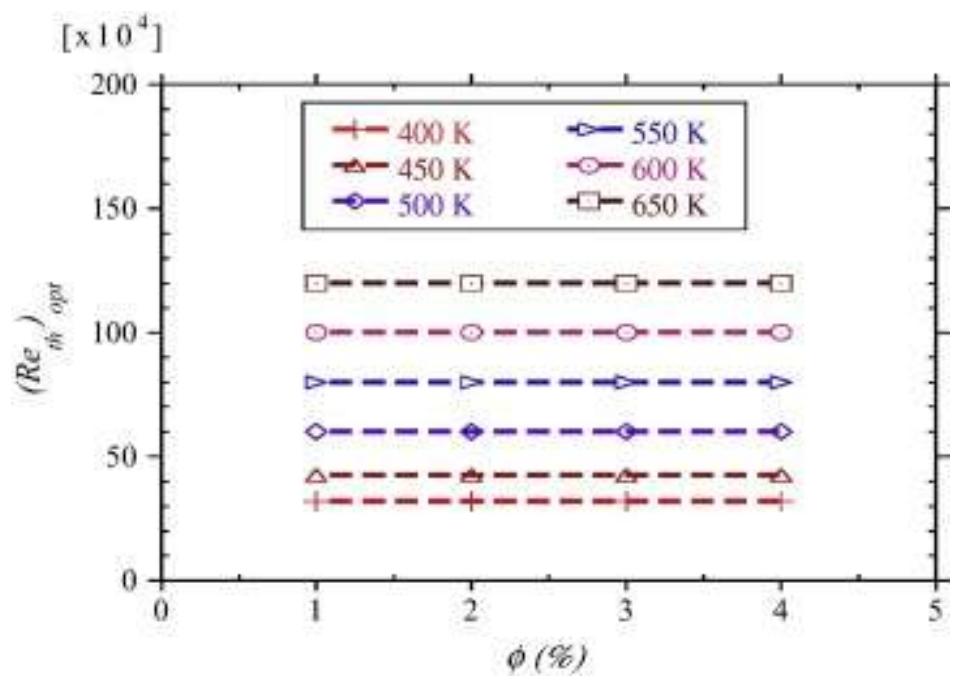

Fig. 12. The Reynolds number below which the thermodynamic performance of the receiver is significantly improved with the use of nanofluids

The Reynolds number under which the thermodynamic performance increases was determined using non-linear regression and is given by the following equation:

$$
\left(\operatorname{Re}_{t h}\right)_{o p t}=115500 \tilde{\phi}^{0.000355} \tilde{\theta}^{3.241}
$$

In Eq. (46), the volume fraction has been non-dimensionalised as $\tilde{\phi}=\phi / \phi_{\text {ref }}$ with $\phi_{\text {ref }}=1 \%$. The inlet temperature is non-dimensionalised as $\tilde{\theta}=T_{i n} / T_{a}$. An ambient temperature of $300 \mathrm{~K}$ used in the simulations is taken as $T_{a m b}$ in the non-dimensionalising of temperature. Eq. (46) predicts the Reynolds number below which there are significant reductions in entropy generation rates within $\pm 3 \%$ and with an $R^{2}$ value of 0.98 . The equation is valid for all the nanofluids and for the values 
presented in Table 1 with a concentration ratio of 113. It should be noted that even though the Reynolds number increases with temperature, flow rates corresponding to these Reynolds numbers are in the range of $50 \mathrm{~m}^{3} \mathrm{~h}^{-1}$ to $68 \mathrm{~m}^{3} \mathrm{~h}^{-1}$. These flow rates are well above the flow rates of about $31.8 \mathrm{~m}^{3} \mathrm{~h}^{-1}$ [34] in practical parabolic trough solar energy systems. These flow rates are also well above the flow rates that give the optimum thermal efficiencies of $20 \mathrm{~m}^{3} \mathrm{~h}^{-1}$ to $40 \mathrm{~m}^{3} \mathrm{~h}^{-1}$ in this study. Thus, for the range of flow rates in actual parabolic trough solar energy systems, using nanofluids improves the thermal and thermodynamic performance. Therefore, for flow rates in practical system and with heat transfer enhancement using nanofluids, higher useful energy outputs are obtained and less of the available energy is destroyed due to reduced irreversibilities. This improvement in performance is essential to make energy from concentrated solar power systems cost competitive with energy from other sources. With lower energy costs, increased deployment of the technology will be possible and thus ensuring a cleaner and widely available source of energy.

\subsection{Enhancement at different concentration ratios}

\subsubsection{Thermal performance}

The performance of a parabolic trough receiver enhanced with nanofluids at different concentration ratios was investigated to determine the possible performance improvement at the different concentration ratios. The performance is investigated using copper-Therminol@VP-1 nanofluid and for a parabolic trough solar energy system with concentration ratios of 88, 100 and 133 using similar boundary conditions as detailed in Section 4.3 and the simulation parameters that are shown in Table 1.

Figure 13(a) to (c) depicts the variation of the thermal efficiency of the parabolic trough solar energy with flow rate at different concentration ratios at an inlet temperature of $500 \mathrm{~K}$ with $\phi=0$ and $\phi=4 \%$, at an inlet temperature of $600 \mathrm{~K}$ with $\phi=0$ and $\phi=4 \%$ and at inlet temperature of $600 \mathrm{~K}$ with $\phi=0$ and $\phi=6 \%$, respectively. From Fig. 13, it is clear that, at a given temperature, flow rate and volume fraction, the thermal efficiency reduces with increasing concentration ratios. This is expected, since the absorber tube temperature will increase with increasing concentration ratio, which leads to a higher receiver thermal loss and thus lower efficiencies at a given volumetric flow rate. The thermal efficiency of the system was shown to reduce by about $4.5 \%$ at any given flow rate as the concentration ratio increased from 88 to 113 . 
One way of ensuring improved thermal performance as the concentration ratios increase is to enhance the convective heat transfer performance of the receiver. As shown in Fig.13(a), for an inlet temperature of $500 \mathrm{~K}$ and volume fractions of $0 \%$ and $4 \%$, the thermal efficiency of the highest concentration ratio parabolic trough solar energy system increases with the use of nanofluids to values of the lowest concentration ratio system with no heat transfer enhancement. As depicted in the figure, the thermal efficiency curve for a concentration ratio of 113 and a volume fraction of $4 \%$ coincides with that of a system with a concentration ratio of 88 and a volume fraction of $0 \%$. This implies that with heat transfer enhancement, the thermal efficiency of high concentration ratio systems can be improved and become similar to that of state-of-theart parabolic trough systems. With high concentration ratio parabolic trough solar energy systems, significant cost reductions can be achieved, since fewer drives and controls are used. Further cost reductions might be achieved with more energy output owing to the achieved improved thermal efficiencies with heat transfer enhancement. In Fig. 13(b) and 13(c), it is clear that significant improvements in performance are achieved with the use of nanofluids.

It is also evident that, at higher temperatures, the improvement in thermal performance is higher than at lower temperatures. This is expected, since with higher temperatures, any reduction in temperature significantly reduces the receiver's thermal loss and increases thermal performance. It was observed that the increase in thermal performance as the volume fraction increases is higher at higher concentration ratios than at lower concentration ratios. This is also expected, since higher concentration ratios will result in higher absorber tube temperatures and higher receiver thermal losses, so that any improvement in performance reduces these temperatures and improves the thermal performance. In this study, it has been shown that at the highest concentration ratio of 113 , the increase in thermal efficiency is about $5 \%$ higher than the increase in thermal efficiency at a concentration ratio of 88 (the lowest considered in this study).

From Fig. 13, the existence of an optimal point at which the thermal efficiency attains a maximum is shown. This was obtained and plotted against the inlet temperature considered. The optimal flow rate is about $22.5 \mathrm{~m}^{3} \mathrm{~h}^{-1}$ and is independent of the temperature used. Even though this is the optimum flow rate based on the thermal efficiency, other factors, such as the need to ensure that receiver temperature gradients are within the safe operating limits, should be used to determine the true operating flow rate. In this work, it was shown that, for flow rates ranging 
from the optimum flow rate up to a flow rate of $40 \mathrm{~m}^{3} \mathrm{~h}^{-1}$, the thermal efficiency reduces by less than $0.5 \%$, as can be seen in Fig. 13. This is probably due to the fact that with increasing flow rates, a point is reached where the gain in thermal performance becomes less than the increase in pumping power and the thermal efficiency starts to gradually decrease. Since using nanofluids improves the thermal performance but also result in higher pumping power requirements, the flow rate at which the optimum thermal efficiency occurs is only slightly higher than that at lower volume fractions as the volume fraction increases. This is most likely due to the useful energy transfer rate and pumping power relationship in Eq. (12), at each volume fraction the useful energy transferred increases with flow rate, the pumping power also increase with flow rate. At some flow rate, the useful energy transferred remains almost constant since at high flow rates the outlet temperature is reduced by a very small amount. However, the pumping power will continue to increase as the flow rate increases, causing the thermal efficiency to start decreasing. It appears from this analysis that the value of the flow rate at which the increase in pumping power becomes more than the increase in performance is almost independent of the volume fraction. Moreover, the pumping power is a small fraction of the useful energy transferred, about $0.50 \%$ at a flow rate of $44.9 \mathrm{~m}^{3} \mathrm{~h}^{-1}$ increasing to $5.3 \%$ at $102 \mathrm{~m}^{3} \mathrm{~h}^{-1}$. Thus, flow rates between $22.5 \mathrm{~m}^{3} \mathrm{~h}^{-1}$ and $40 \mathrm{~m}^{3} \mathrm{~h}^{-1}$ will give thermal efficiencies that are reasonably close to the optimum operating point. Even though, the flow rate does not change significantly with volume fraction and temperature at the optimal point, the optimal thermal efficiency reduces with increasing temperature and increases with increasing volume fraction. 


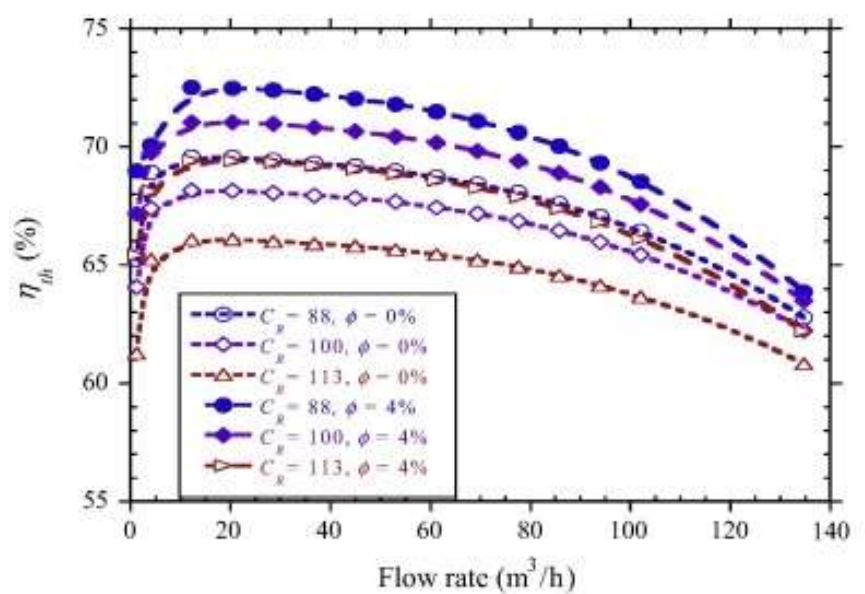

(a)

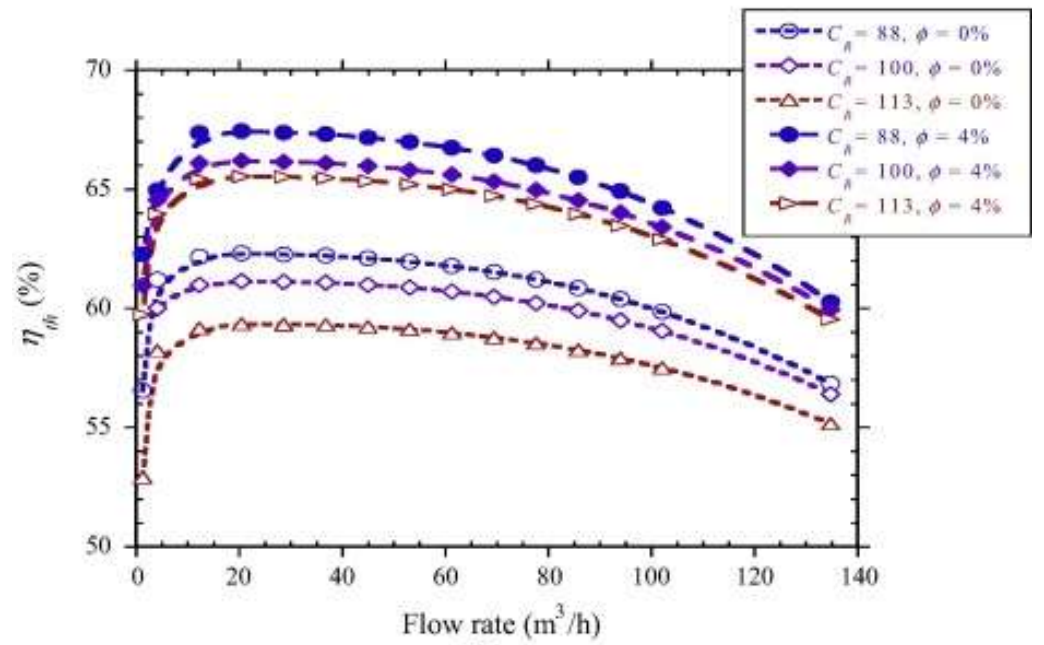

(b)

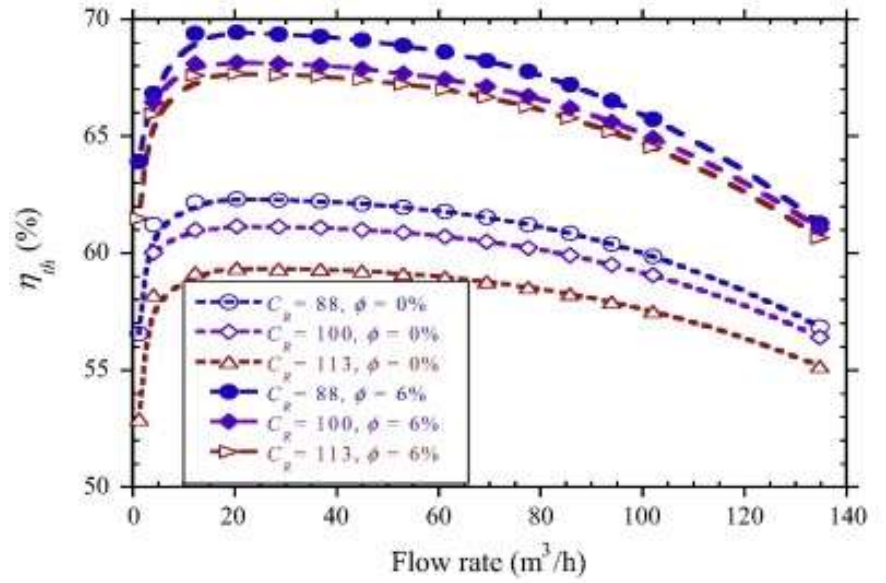

(c)

Fig. 13. Thermal efficiency as a function of flow rate at different concentration ratios for: (a) an inlet temperature of $500 \mathrm{~K}$ with $\phi=0$ and $\phi=4 \%$, (b) an inlet temperature of $600 \mathrm{~K}$ with $\phi=0$ and $\phi=4 \%$ and (c) an inlet temperature of $600 \mathrm{~K}$ with $\phi=0$ and $\phi=6 \%$ 
Figure 14 shows the plot of the optimal thermal efficiency with an inlet temperature at different volume fractions at a concentration ratio of 100. The same trend was obtained at the other two concentration ratios, but the thermal efficiencies are higher at a concentration ratio of 88 than at a concentration ratio of 113 for the reasons discussed earlier. The optimal thermal efficiency generally decreases with increasing inlet temperatures, owing to the high thermal loss at high absorber tube temperatures. Also shown is that the optimal thermal efficiency increases as the volume fraction increases. This is expected since the thermal performance improves with increasing volume fractions.

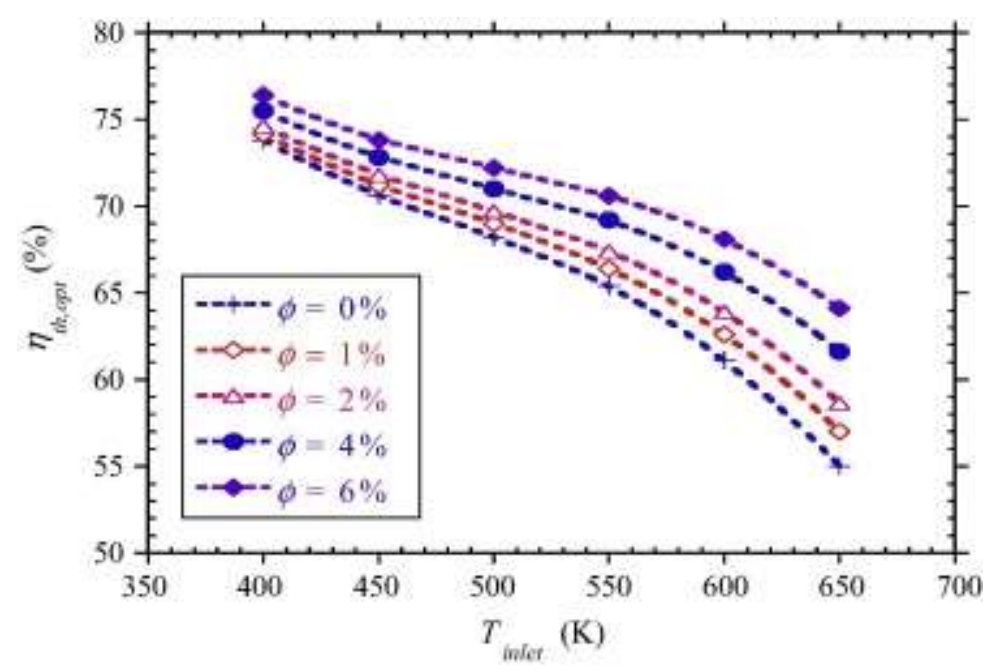

Fig. 14. Optimal thermal efficiency as a function of inlet temperature at different volume fractions for copperTherminol ${ }^{\circledR V P}-1$ and concentration ratio of 100

At all the concentration ratios, inlet temperatures and other considered parameters, as given in Table 1, the optimal thermal efficiency occurs at a flow rate of about $22.5 \mathrm{~m}^{3} \mathrm{~h}^{-1}$. Significant increases in the optimal thermal efficiency are shown as the inlet temperatures increase. With higher inlet temperatures, absorber tube temperatures will increase, and this reduces the thermal efficiency due to the high receiver thermal loss. Thus, with heat transfer enhancement, the improvement in thermal performance leads to higher thermal efficiencies and significant increments in the thermal efficiency when compared to those at low temperatures. The optimal thermal efficiency is correlated by the following equation:

$\left(\eta_{\text {th }}\right)_{\text {opt }}=179(\tilde{\phi}+1)^{0.04176} \tilde{\theta}^{-0.4166} C_{R}^{-0.1708}$ 
Similar to Eq. (46), $\widetilde{\phi}$ is the non-dimensionalised volume fraction, and $\widetilde{\theta}$ is the non dimensionalised inlet temperature. Eq. (47) is valid for the range of parameters presented in Table 1 and volume fractions $0 \leq \phi \leq 6 \%$ and predicts the optimal thermal efficiency within $\pm 3 \%$.

\subsubsection{Thermodynamic performance}

The parabolic trough receiver's thermodynamic performance is presented using entropy generation rates as a result of both heat transfer and fluid friction irreversibilities. In an earlier study, it was shown that the entropy generation rates increase with increasing concentration ratios [45]. In this study, it is also shown that, at a given inlet temperature, flow rate and volume fraction, the entropy generation rate increases as the concentration ratio increases as depicted in Fig. 15. This is expected, since an increase in the concentration ratios results in an increase in the finite temperature differences of the receiver, which leads to much higher heat transfer irreversibilities, resulting in increased entropy generation rates.

With heat transfer enhancement, especially at low Reynolds numbers, the improvement in heat transfer performance leads to lower temperature gradients in the receiver thus lower entropy generation rates. As depicted in Fig. 15, the entropy generation rates are shown to reduce significantly with increasing volume fraction for Reynolds numbers lower than that beyond which the enhancement of convective heat transfer enhancement does not result in better thermodynamic performance. Equation (46) provides an acceptable prediction of the Reynolds number beyond which using nanofluids results in no improvement of the receiver's thermodynamic performance. For all the concentration ratios and inlet temperatures, flow rates lower than $45 \mathrm{~m}^{3} \mathrm{~h}^{-1}$ result in significant improvements of the receiver's thermodynamic performance.

A further visualisation of the effect of heat transfer enhancement using nanofluids at different concentration ratios is depicted in Fig. 16 using the Bejan number. The Bejan number is defined as the ratio of the entropy generation due to the heat transfer irreversibility to the total entropy generation rate. With heat transfer enhancement, it is essential that the heat transfer irreversibility is reduced without a significant increase in the fluid flow irreversibility. The heat transfer irreversibility is the dominant source of the entropy generation rate at low Reynolds numbers, while the fluid friction irreversibility dominates at higher Reynolds numbers. As shown 
in Fig. 16, at a given Reynolds number, concentration ratio and inlet temperature, the Bejan number reduces as the volume fraction increases and the Reynolds number increases.

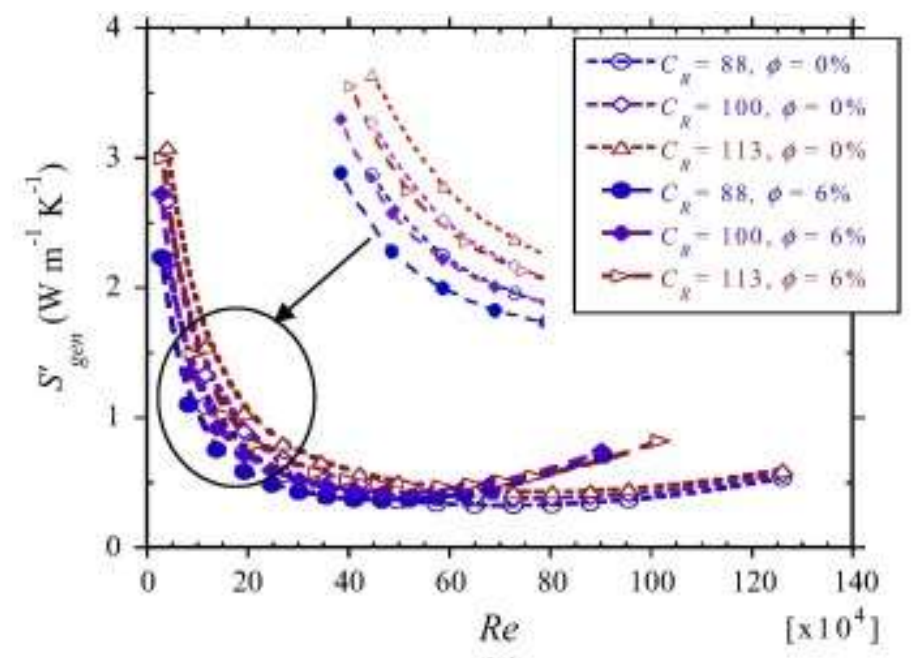

(a)

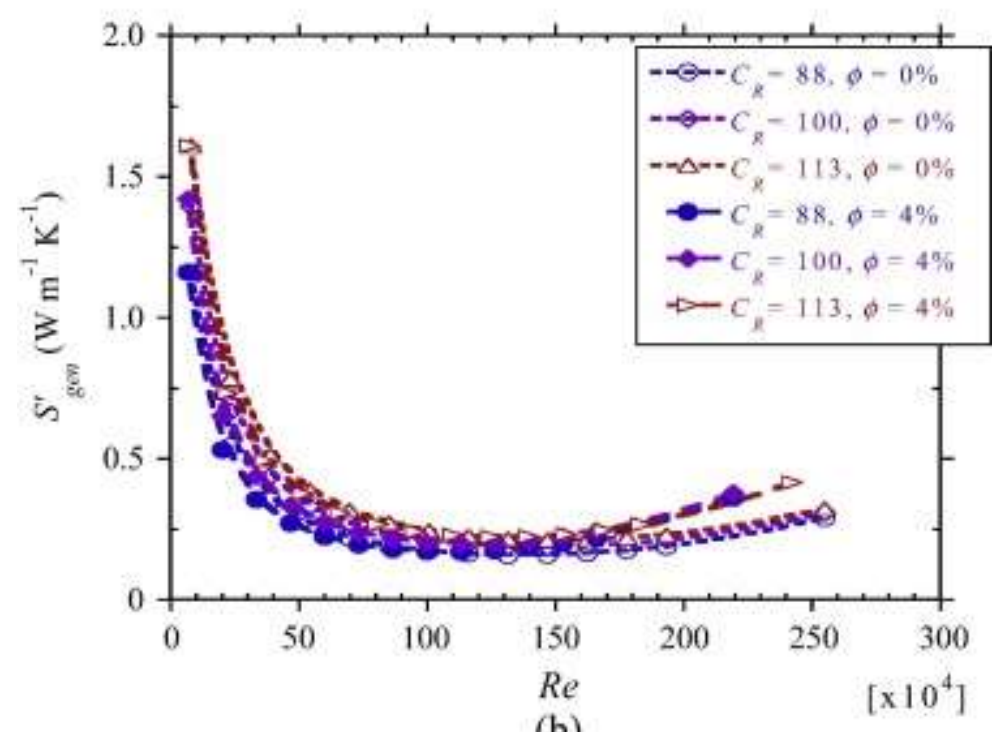

(b)

Fig. 15. Entropy generation rate as a function of Reynolds number at different concentration ratios (a) for an inlet temperature of $450 \mathrm{~K}$ with $\phi=0$ and $\phi=6 \%$ and (b) for an inlet temperature of $600 \mathrm{~K}$ with $\phi=0$ and $\phi=4 \%$

The reduction in the Bejan number with volume fraction mainly occurs due to increased heat transfer performance at low Reynolds numbers and due to both improved heat transfer performance and an increase in the fluid friction irreversibility as the Reynolds numbers increase. The reduction in the Bejan number with increasing Reynolds numbers is also due to improved heat transfer performance and increased fluid friction irreversibility as the Reynolds 
numbers increase. As shown, at low Reynolds numbers, the Bejan number is about 1, implying that the heat transfer irreversibility dominates the entropy generation budget. As the Reynolds numbers increase, the Bejan number reduces, since the heat transfer irreversibility reduces with improved heat transfer performance and the fluid friction irreversibility increases due to higher pressure drops. The Bejan number will approach zero if the fluid friction irreversibility becomes the only form of irreversibility.

As shown in the preceding discussion, heat transfer enhancement of receiver tubes of parabolic trough solar energy systems has potential to greatly improve both the thermal and thermodynamic performance of these systems. For flow rates similar to those in practical parabolic trough solar energy systems, the use of nanofluids improves the heat transfer performance significantly and thus more energy output from the system. Besides, the reduction in entropy generation rates means less destruction of available energy. Moreover, the use of high concentration ratio parabolic trough systems together with heat transfer enhancement shows an enormous potential for improved energetic and exergetic performance of these systems. With advances in research and development, the cost of energy from concentrated solar power systems is expected to reduce significantly, making energy from these systems cost competitive with that from conventional energy systems. For example, the development of high concentration ratio systems is expected to cut solar field costs significantly, up to $20 \%$ in some cases $[9,10]$. 


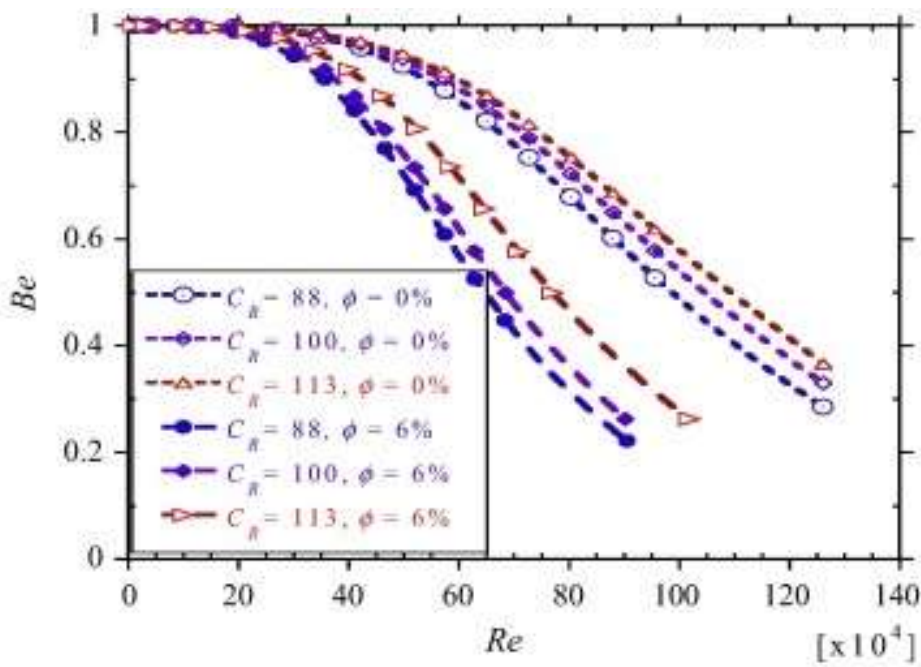

(a)

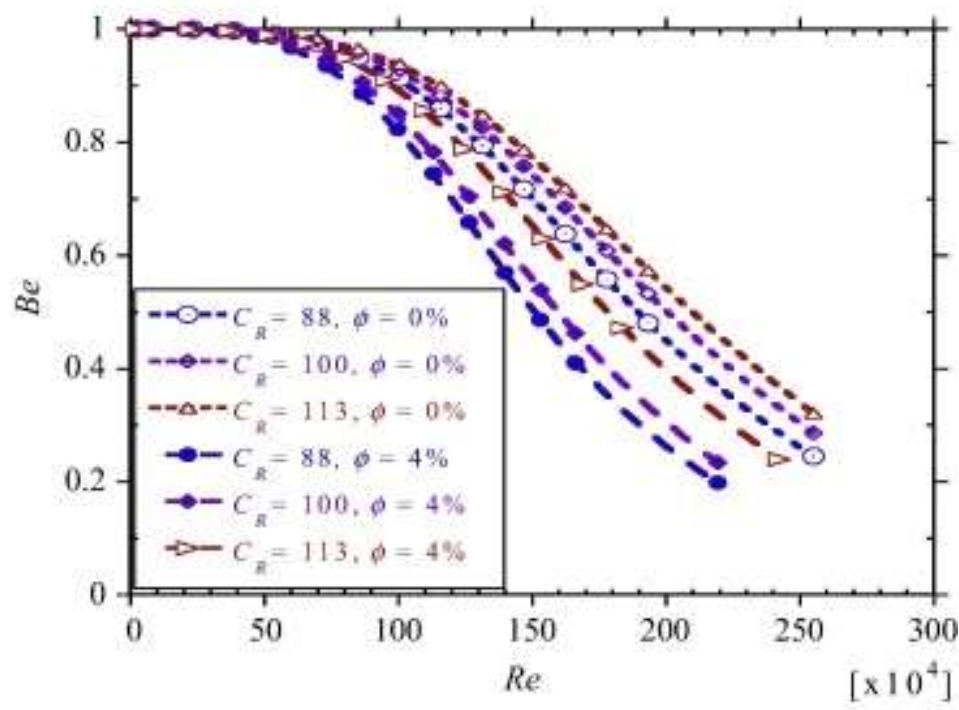

(b)

Fig. 16. Bejan number as a function of Reynolds number at different concentration ratios for: (a) an inlet temperature of $450 \mathrm{~K}$ with $\phi=0$ and $\phi=6 \%$ and (b) an inlet temperature of $600 \mathrm{~K}$ with $\phi=0$ and $\phi=4 \%$

\section{Conclusion}

In this study, the optimum thermal and thermodynamic performance of a parabolic trough solar energy system using different nanofluids namely silver-Therminol@VP-1, copperTherminol@VP-1 and $\mathrm{Al}_{2} \mathrm{O}_{3}$-Therminol ${ }^{\circledR} \mathrm{VP}-1$, was investigated and presented. Results showed that the use of nanofluids improves the thermal and thermodynamic performance of the system. With the increased energy output from the system due to heat transfer enhancement, the thermal 
efficiency of the parabolic trough solar energy system was shown to increase by $13.9 \%, 12.5 \%$ and $7.2 \%$ for silver-Therminol ${ }^{\circledR V P}-1$, copper-Therminol®VP-1 and $\mathrm{Al}_{2} \mathrm{O}_{3}$-Therminol®VP-1 nanofluids as the volume fraction increased from 0 to $6 \%$.

At each volume fraction, there is a flow rate or Reynolds number at which the thermal efficiency is a maximum. It was shown that the optimal thermal efficiency at each temperature and volume fraction was almost independent of the inlet temperature, volume fraction and type of nanofluid considered. For all the nanofluids and range of considered parameters, the optimal flow rate was about $22.5 \mathrm{~m}^{3} \mathrm{~h}^{-1}$.

Furthermore, the influence of heat transfer enhancement using nanofluids on the thermal and thermodynamic performance of a parabolic trough solar energy system at different concentration ratios was investigated. It was shown that the flow rate that gives the optimum thermal efficiency at the different concentration ratios was almost similar to the previous value of $22.5 \mathrm{~m}^{3} \mathrm{~h}^{-1}$. It was also shown that, with heat transfer enhancement, the thermal performance of the high concentration parabolic trough solar energy system is higher than or can be restored to values close to those of the low concentration. The improvement in thermal performance of the highest concentration ratio system $\left(C_{R}=113\right)$ was shown to be about $5 \%$ higher than that of the lowest concentration system $\left(C_{R}=88\right)$. As such, there exists significant potential for improved energetic and exergetic performance with heat transfer enhancement in parabolic trough solar energy systems with high concentration ratios.

\section{Acknowledgement}

This work is based on research supported in part by the National Research Foundation (NRF) (Grant No. 9927). The grant holder acknowledges that the opinions, findings and conclusions or recommendations expressed in any publication generated by the NRF-supported research are those of the authors and that the NRF accepts no liability whatsoever in this regard. The support received from the University of the Witwatersrand, Johannesburg and the University of Pretoria is also duly acknowledged and appreciated. 


\section{References}

[1] Philibert C, Frankl P. International Energy Agency, Technology roadmap: concentrating solar power, IEA/OECD, 2010, Paris, France.

[2] Frank L. Overview of parabolic troughs and linear Fresnel receivers. IEA CSP Workshop March 2014:1-16.

[3] SunShot Initiative. Available at: http://www1.eere.energy.gov/solar/sunshot/index.html. US Department of Energy [accessed 01.02.2016].

[4] Price H, Kearney D. Parabolic-trough technology roadmap: A pathway for sustained commercial development and deployment of parabolic trough technology. NREL Technical Report, January 1999; NREL/TP-550-24748:1-35.

[5] SunShot Initiative-High-concentration low cost parabolic trough system for baseload CSP. Available at: http://www1.eere.energy.gov/solar/sunshot/csp_baseload_skyfuel.html. US Department of Energy [accessed 01.12.2014].

[6] Lüpfert E, Geyer M, Schiel W, Esteban A, Osuna R, Zarza E, Nava P. Eurotrough design issues and prototype testing at PSA. Proceedings of Solar Forum 2001- Solar energy: The power to choose, April 21-25, 2001, Washington DC.

[7] Geyer M, Lüpfert E, Osuna R, Esteban A, Schiel W, Schweitzer A, Eduardo Z, Nava P, Langenkamp J, Mandelberg E. EuroTrough - Parabolic trough collector developed for cost efficient solar power generation. $11^{\text {th }}$ SolarPACES international symposium on concentrated solar power and chemical energy technologies, September 4-6, 2002, Zurich Switzerland: 1-7.

[8] Price H, Lüpfert E, Kearney D, Zarza E, Cohen G, Gee R, Mahoney R. Advances in parabolic trough solar power technology. Sol Energy Eng 2002;124:109-25.

[9] SkyTrough ${ }^{\circledR}$ product information: Next-generation solar parabolic tough technology. www.skyfuel.com/downloads/brochure/SkyTroughBrochure.pdf [accessed 15.08.2015].

[10] Hoste G, Schuknecht N. Thermal efficiency analysis of SkyFuel's advanced, large-aperture, parabolic trough collector. Energy Procedia 2015; 69:96-105. 
[11] Ravi Kumar K, Reddy KS. Thermal analysis of solar parabolic trough with porous disc receiver. Appl Energy 2009; 86:1804-12.

[12] Mwesigye A, Bello-Ochende T, Meyer JP. Heat transfer and thermodynamic performance of a parabolic trough receiver with centrally placed perforated plate inserts. Appl Energy 2014; 136:989-1003.

[13] Muñoz J, Abánades A. Analysis of internal helically finned tubes for parabolic trough design by CFD tools. Appl Energy 2011;88:4139-49.

[14] Fuqiang W, Qingzhi L, Huaizhi H, Jianyu T. Parabolic trough receiver with corrugated tube for improving heat transfer and thermal deformation characteristics. Appl Energy 2016;164:41124.

[15] Fuqiang W, Zhexiang T, Xiangtao G, Jianyu T, Huaizhi H, Bingxi L. Heat transfer performance enhancement and thermal strain restrain of tube receiver for parabolic trough solar collector by using asymmetric outward convex corrugated tube. Energy 2016;114:275-92.

[16] Wang P, Liu DY, Xu C. Numerical study of heat transfer enhancement in the receiver tube of direct steam generation with parabolic trough by inserting metal foams. Appl Energy 2013;102:449-60.

[17] Cheng ZD, He YL, Cui FQ. Numerical study of heat transfer enhancement by unilateral longitudinal vortex generators inside parabolic trough solar receivers. Int J Heat Mass Trans 2012;55:5631-41.

[18] Mahian O, Kianifar A, Kalogirou SA, Pop I, Wongwises S. A review of the applications of nanofluids in solar energy. Int J Heat Mass Transfer 2013;57:582-94.

[19] Kasaeian A, Eshghi AT, Sameti M. A review on the applications of nanofluids in solar energy systems. Renewable and Sustainable Energy Reviews 2015;43:584-98.

[20] Li X, Zou C, Zhou L, Qi A. Experimental study on the thermo-physical properties of diathermic oil based $\mathrm{SiC}$ nanofluids for high temperature applications. Int J Heat Mass Transfer 2016;97:631-7. 
[21] Lee S, Choi SUS, Li S, Eastman JA. Measuring thermal conductivity of fluids containing oxide nanoparticles. ASME J Heat Transfer 1999;121:280-289.

[22] Colangelo G, Favale E, Miglietta P, Milanese M, de Risi A. Thermal conductivity, viscosity and stability of $\mathrm{Al}_{2} \mathrm{O}_{3}$-diathermic oil nanofluids for solar energy systems. Energy 2016;95:12436.

[23] Colangelo G, Favale E, de Risi A, Laforgia D. Results of experimental investigations on the heat conductivity of nanofluids based on diathermic oil for high temperature applications. Appl Energy 2012;97:828-33.

[24] Verma SK, Tiwari AK. Progress of nanofluid application in solar collectors: A review. Energy Conversion and Management 2015;100:324-46.

[25] Waghole DR, Warkhedkar RM, Kulkarni VS, Shrivastva RK. Experimental investigations on heat transfer and friction factor of silver nanofliud in absorber/receiver of parabolic trough collector with twisted tape inserts. Energy Procedia 2014;45:558-67.

[26] Sokhansefat T, Kasaeian AB, Kowsary F. Heat transfer enhancement in parabolic trough collector tube using $\mathrm{Al}_{2} \mathrm{O}_{3}$ /synthetic oil nanofluid. Renewable and Sustainable Energy Reviews 2014;33:636-44.

[27] Taylor AR, Phelan EP, Otanicar PT, Walker AC, Nguyen M, Trimble S, Prasher R. Applicability of nanofluids in high flux solar collectors. Renewable Sustainable Energy 2011;023104:1-15.

[28] Mwesigye A, Huan Z, Meyer JP. Thermodynamic optimisation of the performance of a parabolic trough receiver using synthetic oil- $\mathrm{Al}_{2} \mathrm{O}_{3}$ nanofluid. Appl Energy 2015;156:398-412.

[29] Mwesigye A, Huan Z, Meyer JP. Thermal performance and entropy generation analysis of a high concentration ratio parabolic trough solar collector with $\mathrm{Cu}$-Therminol@VP-1 nanofluid. Energy Conversion and Management 2016; 120:449-65.

[30] Bellos E, Tzivanidis C, Antonopoulos KA, Gkinis G. Thermal enhancement of solar parabolic trough collectors by using nanofluids and converging-diverging absorber tube. Renewable Energy 2016;94:213-22. 
[31] Amina B, Miloud A, Samir L, Abdelylah B, Solano JP. Heat transfer enhancement in a parabolic trough solar receiver using longitudinal fins and nanofluids. Journal of Thermal Science 2016;25:410-7.

[32] Chen M, He Y, Zhu J, Wen D. Investigating the collector efficiency of silver nanofluids based direct absorption solar collectors. Appl Energy 2016;181:65-74.

[33] Moens L, Blake DM. Mechanism of hydrogen formation in solar parabolic trough receivers. J Sol Energ-T ASME 2010;132:031006.

[34] Forristall R. Heat transfer analysis and modeling of a parabolic trough solar receiver implemented in Engineering Equation solver. NREL Technical Report, October 2003; NREL/TP-550-34169:1-145.

[35] Duffie JA, Beckman WA. Solar Engineering of Thermal Processes. 3rd ed. Hoboken, New Jersey: John Wiley and Sons Inc., 2006.

[36] Soteris K. Solar Energy Engineering: Processes and Systems. 2nd ed. United Kingdom: Academic Press, 2013.

[37] Mullick SC, Nanda SK. An improved technique for computing the heat loss factor of a tubular absorber. Solar Energy 1989;42:1-7.

[38] Swinbank WC. Long-wave radiation from clear skies. Q J R Meteorol Soc 1963;89:339-48.

[39] Burkholder F, Kutscher C. Heat loss testing of Schott's 2008 PTR70 parabolic trough receiver. NREL Technical Report, 2009; NREL/TP - 550-45633:1-58.

[40] Wirz M, Petit J, Haselbacher A, Steinfeld A. Potential improvements in the optical and thermal efficiencies of parabolic trough concentrators. Solar Energy 2014;107:398-414.

[41] Mwesigye A, Bello-Ochende T, Meyer JP. Heat transfer and entropy generation in a parabolic trough receiver with wall-detached twisted tape inserts. International Journal of Thermal Sciences 2016;99:238-57.

[42] Bejan A. Entropy Generation Minimization: the Method of Thermodynamic Optimization of Finite-Size Systems and Finite-Time Processes. Boca Raton, Fla.: CRC Press, 1996. 
[43] Kock F, Herwig H. Local entropy production in turbulent shear flows: a high-Reynolds number model with wall functions. Int J Heat Mass Trans 2004;47:2205-15.

[44] Herwig H, Kock F. Direct and indirect methods of calculating entropy generation rates in turbulent convective heat transfer problems. Heat and Mass Transfer 2007;43:207-15.

[45] Mwesigye A, Bello-Ochende T, Meyer JP. Minimum entropy generation due to heat transfer and fluid friction in a parabolic trough receiver with non-uniform heat flux at different rim angles and concentration ratios. Energy 2014;73:606-17.

[46] NREL. SolTrace optical modelling software. SolTrace 2012;2012.7.9.

[47] Schott's PTR70 Receiver: Available at: http://www.schott.com/csp/english/schott-solar-ptr70-receivers.html [accessed 24. 09.2016].

[48] Wendelin T. Parabolic trough VSHOT optical characterization in 2005-2006. Presented at the parabolic trough technology workshop, Incline Village, Nevada, $14^{\text {th }}-16^{\text {th }}$ February, NREL/PR-550-40024.

[49] ANSYS® Academic research, release 14.5, ANSYS FLUENT, theory guide, Cannonsburg, PA, ANSYS, Inc.

[50] Shih T, Liou WW, Shabbir A, Yang Z, Zhu J. A new k- $€$ eddy viscosity model for high reynolds number turbulent flows. Comput Fluids 1995;24:227-38.

[51] Solutia technical bulletin 7239115C-Therminol®VP-1. Available at: https://www.therminol.com/products/Therminol-VP1 [accessed 05.04.2016].

[52] Incropera PF, DeWitt P,David, Bergman L,Theodore, Lavine S,Adrienne. Fundamentals of Heat and Mass Transfer. 6th ed. US: John Wiley \& Sons, 2006.

[53] Ebrahimi A, Rikhtegar F, Sabaghan A, Roohi E. Heat transfer and entropy generation in a microchannel with longitudinal vortex generators using nanofluids. Energy 2016;101:190-201.

[54] Seyf HR, Feizbakhshi M. Computational analysis of nanofluid effects on convective heat transfer enhancement of micro-pin-fin heat sinks. International Journal of Thermal Sciences 2012;58:168-79. 
[55] Manca O, Mesolella P, Nardini S, Ricci D. Numerical study of a confined slot impinging jet with nanofluids. Nanoscale Res Lett 2011;6:188,276X-6-188.

[56] Li P, Zhang D, Xie Y. Heat transfer and flow analysis of $\mathrm{Al}_{2} \mathrm{O}_{3}$-water nanofluids in microchannel with dimple and protrusion. Int J Heat Mass Transfer 2014;73:456-67.

[57] Maïga SEB, Palm SJ, Nguyen CT, Roy G, Galanis N. Heat transfer enhancement by using nanofluids in forced convection flows. Int J Heat Fluid Flow 2005;26:530-46.

[58] Bruggeman VD. Berechnung verschiedener physikalischer Konstanten von heterogenen Substanzen. I. Dielektrizitätskonstanten und Leitfähigkeiten der Mischkörper aus isotropen Substanzen. Ann Phys 1935;7:636-64.

[59] Buongiorno J, Venerus DC, Prabhat N, McKrell T, Townsend J, Christianson R et al. A benchmark study on the thermal conductivity of nanofluids. J Appl Phys 2009;106.

[60] ANSYS® Academic research, release 14.5, ANSYS FLUENT user's guide, Cannonsburg, PA, ANSYS, Inc.

[61] Jeter SM. Calculation of the concentrated flux density distribution in parabolic trough collectors by a semifinite formulation. Solar Energy 1986;37:335-45.

[62] He Y, Xiao J, Cheng Z, Tao Y. A MCRT and FVM coupled simulation method for energy conversion process in parabolic trough solar collector. Renew Energ 2011;36:976-85.

[63] Yang B, Zhao J, Xu T, Zhu Q. Calculation of the concentrated flux density distribution in parabolic trough solar concentrators by Monte Carlo ray-trace method. In: Proceedings of Symposium on Photonics and Optoelectronic (SOPO), $19^{\text {th }}-21^{\text {st }}$ June, Chengdu, China, pp. 1-4.

[64] Dudley EV, Kolb JG, Mahoney AR, Mancini T, R., Sloan M, Kearney D. Test results: SEGS LS-2 solar collector. Sandia National Laboratory 1994;SAND94-1884.

[65] Dreyer S, Eichel P, Gnaedig T, Hacker Z, Janker S, Kuckelkorn T, Silmy K, Pernpeintner J, Luepfert, E. Heat loss measurements on parabolic trough receivers. SolarPACES 2010. 